\title{
Estado de la deforestación y estadísticas socioeconómicas y ambientales recientes en las zonas ocupadas por colonos del el territorio indígena Mayangna Sauni As en BOSAWAS'
}

\author{
Ramón Guevara Flores ${ }^{2}$ \\ Gobierno Territorial Indígena Mayangna Sauni As (MSA)
}

\section{CONTEXTO DE REALIZACIÓN DEL ESTUDIO}

La aprobación, en 2013, de la Ley No. 445: "Régimen de Propiedad Comunal de los Pueblos Indígenas y Comunidades Étnicas de las Regiones Autónomas de la Costa Atlántica y de los Ríos, Bocay, Coco, Indio y Maíz" representó un gran avance para el proceso de autonomía en la Costa Caribe de Nicaragua. Con este marco jurídico se reconoció y protegió jurídicamente el derecho colectivo sobre la propiedad ancestral, territorial y comunal, y se establecieron formalmente las autoridades comunitarias y territoriales indígenas y afrodescendientes. Estos derechos adquirieron mayor respaldo jurídico internacional con la aprobación de la Declaración Universal de los Derechos de los Pueblos Indígenas, por parte de los países miembros de las Naciones Unidas de la cual Nicaragua es signataria.

Sobre la base de este marco jurídico institucional, el Territorio Indígena Mayangna Sauni As (MSA) inició, en el año 2010, el proceso de saneamiento de su propiedad ancestral, con el propósito de promover y proteger los derechos y las libertades de su pueblo indígena. En el año 2015, el Gobierno Territorial Indígena MSA, en conjunto con IBIS Dinamarca en Nicaragua, dieron pasos concretos para garantizar la seguridad jurídica del territorio que, con $1,638.10 \mathrm{~km}^{2}$, es considerado el más extenso y virgen de la reserva de biósfera BOSAWAS. La población estimada de MSA es de 10,032 habitantes principalmente ubicados en el municipio de Bonanza.

El presente artículo resume el contenido del estudio "Diagnóstico del Territorio Mayangna Sauni As, en especial aquellas zonas afectadas por la invasión de colonos". Con esto se espera aportar al proceso de saneamiento territorial de MSA, de tal manera que se conozca la situación que afecta a este territorio mayangna en relación a la presencia de colonos invasores en propiedad indígena. De acuerdo a estimaciones técnicas (Humboldt. 2016; GTZ 2007), el nivel de deforestación en la Reserva de Biosfera BOSAWAS es alarmante y se estima que, en un periodo de treinta años, ésta podría desaparecer. Los resultados del estudio-diagnóstico confirman esta realidad y determinan que en el Territorio Mayangna Sauni As, entre los años 1999 - 2015, se perdió un total de 31,000 ha de bosque primario, con una tasa de deforestación anual entre un rango de 700 a $2000 \mathrm{ha} /$ año. En ese sentido, el GTI MSA toma de referencia esta información y exige y denuncia públicamente la urgencia del Saneamiento Territorial, ya que es la única vía viable para la protección y conservación de los recursos naturales de la Reserva de Biosfera BOSAWAS.

El trabajo de investigación se llevó a cabo entre los meses de abril y agosto del año 2015 y contó con la

Última versión.

Autor del artículo y Coordinador del equipo consultor que elaboró de manera participativa el estudio de actualización del “Autodiagnóstico del Territorio Mayangna Sauni As en especial aquellas zonas afectadas por la invasión de colonos”. 2015. Con los respectivos derechos reservados para el GTIMSA e IBIS Dinamarca en Nicaragua. En este Estudio colaboraron en el levantamiento de información en campo: técnicos GTIMSA y Dennis Stanley; en la parte legal: Gizaneta Fonseca con el apoyo de Modesto Frank; en la parte socioeconómica: Melba Mclean; en la parte ambiental: David Bradford; en la parte cartográfica: Orlando Lacayo; y en la parte de base de datos: Miguel Medrano. 

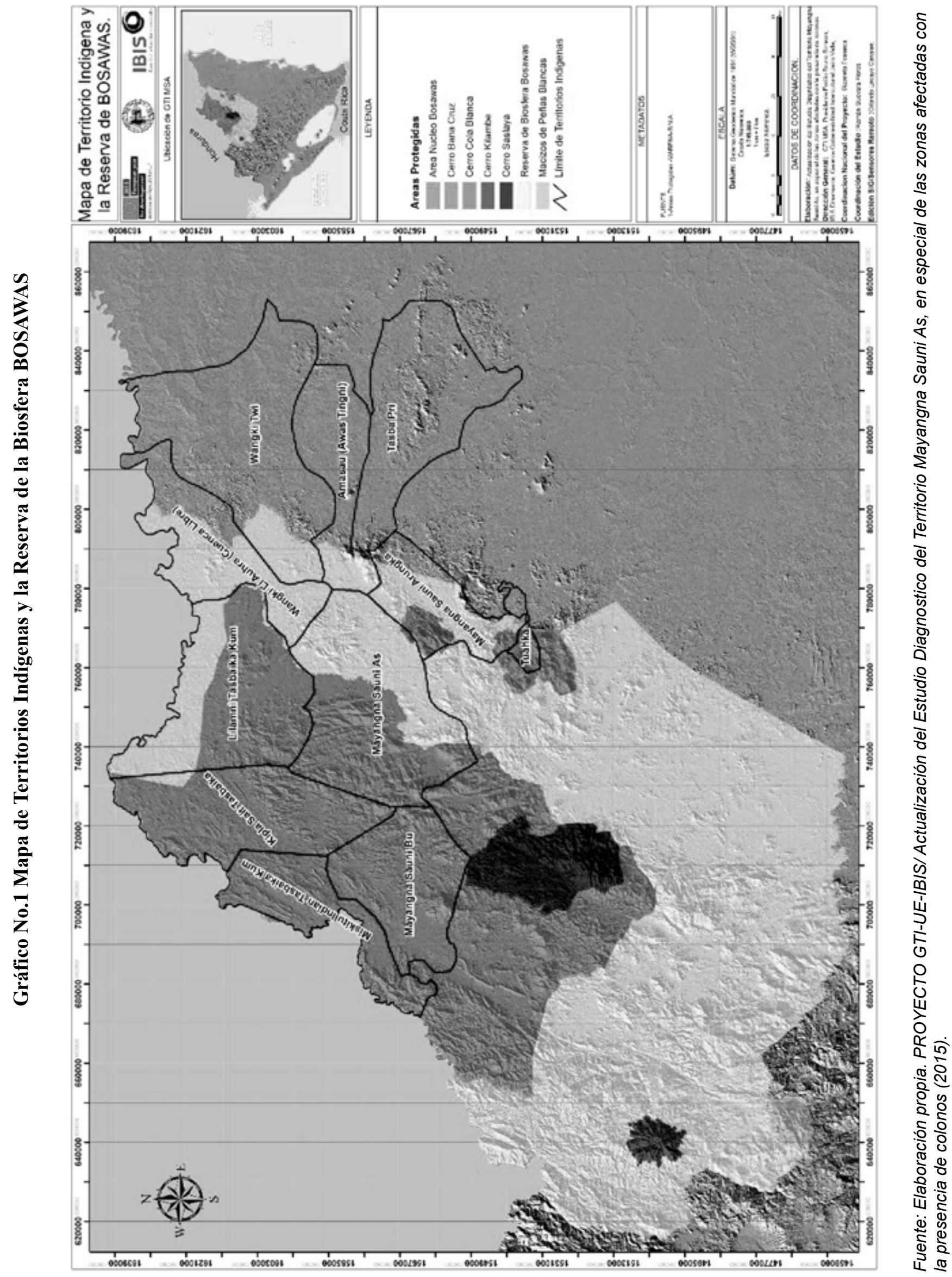
participación del equipo consultor, comunitarios y líderes mayangnas, equipo técnico de IBIS Dinamarca, técnicos de la Nación mayangna y delegados de las instituciones públicas (Alcaldía de Bonanza, el MARENA, el Batallón Ecológico del Ejército de Nicaragua y la Policía Nacional). La actualización del estudio diagnóstico del Territorio Mayangna Sauni As se realizó en el marco de la ejecución del proyecto "Resolución de conflictos sobre tenencia de la tierra que garantice la seguridad jurídica y efectiva del Territorio Indígena Mayangna Sauni As", co financiado por la Delegación de la Comisión Europea en Nicaragua e IBIS Dinamarca y co ejecutado por el Gobierno Territorial Indígena Mayangna Sauni As e IBIS Dinamarca.

\section{¿Por qué es tan urgente y necesario el saneamiento?}

Empecemos ubicando el territorio MSA geográficamente y por su importancia socio-cultural para la Nación mayangna. Los territorios sumo - mayangna son nueve y se asientan en las dos regiones autónomas, con una población aproximada de unas veinte mil personas, un tercio de las cuales habitan en la Reserva de Biosfera BOSAWAS (RBB). Mayangna Sauni As es el territorio considerado la capital de la Nación mayangna y el de mayor extensión de la RBB. Sus comunidades están asentadas en las riberas de los ríos Pispis, Kuahbul, Kahkah y Waspuk. Los territorios que integran la Nación mayangna son: 1) Mayangna Sauni As (Musawas, Bonanza, RACCN); 2) Mayangna Sauni Bu (Amak, San José de Bocay, RACCN); 3) Mayangna Sauni Bas (Sikilta, Siuna, RACCN); 4) Mayangna Sauni Arungka (Ispayul Ilna, Bonanza, RACCN); 5) Mayangna Sauni Tuahka (Wasakin, Rosita, RACCN); 6) Mayangna Sauni Awastingni (Awastingni, Waspan, RACCN); 7) Mayangna Sauni Umra (Umra, Waspan, RACCN); 8) Mayangna Sauni Walakwas (Walakwas, San José de Bocay, Jinotega), y 9) Mayangna Sauni Karawala (Karawala, La Desembocadura de Río Grande, RACCS).

\section{Territorio ancestral Reserva de Biosfera Bosawas (RBB)}

Según Hurtado de Mendoza hay suficiente evidencia en la historia de Nicaragua para postular que los mayangnas estuvieron ampliamente distribuidos por las tierras de la región atlántica de Nicaragua y Honduras, desde la cuenca del río Patuca en el norte hasta la cuenca del río Escondido en el sur. Los pueblos indígenas twahkas y panamahkas (sumos del norte, actualmente mayangnas), denominados como caribes por los españoles que fundaron la provincia de Nicaragua, se asentaron en parte de lo que hoy se conoce como la Reserva de Bosawas hasta bien entrado el siglo XVII. Por lo tanto, en conjunto con el grupo de los ulwas (sumos del sur) y los matagalpas, los twahkas y panamahka poblaron extensamente BOSAWAS, desde mucho tiempo antes de la Colonia.

Hoy en día la relevancia étnica - cultural se manifiesta ya que en el área protegida y en sus alrededores habitan comunidades indígenas y mestizas. En el caso de las comunidades mestizas, en su mayoría se encuentran en la zona de amortiguamiento y su ocupación se debe a que han invadido los territorios indígenas que pertenecen a la zona núcleo de la reserva. Las comunidades indígenas que constituyen BOSAWAS son los territorios mayangnas (Mayangna Sauni As, Mayangna Sauni Bas, Mayangna Sauni Arungka y Mayangna Sauni Bu, ubicados en el centro de BOSAWAS y los ríos Pis-Pis, Waspuk, Bocay y Lakus) y el territorio intercultural mayangna - miskito (Miskitu Indian Tasbaika Kum, ubicado en las márgenes del río Coco o Wangki).

\section{TERRITORIO MAYANGNA SAUNI AS Y SU HISTORIA ANTERIOR A LA INVASION DE COLONOS}

El TMSA tiene una extensión de $1,638.10 \mathrm{~km}^{2}$ y cuenta con una población de 8,300 habitantes. Está ubicado entre los municipios de Bonanza, Waspam, El Cua Bocay y se encuentra distribuido de acuerdo al título de propiedad en un $35 \%$ en el Municipio de Bonanza, un $60 \%$ en el Municipio de Waspam y un 5\% en el Municipio del Cua - Bocay, Departamento de Jinotega. En el año 1993, con el apoyo del Consejo Regional Autónomo de la RAAN se dio inicio al proceso de Demarcación, Delimitación, Documentación Socioeconómica, Mapeo, Carrileo y Amojonamiento del Territorio Mayangna Sauni As, que significa "Primer Territorio Mayangna". Cuando se realizó este proceso no existían colonos o invasores en el territorio, por lo cual se consideró un territorio limpio.

El primer diagnóstico realizado en el territorio MSA ejecutado por TNC se refería específicamente a la población mayangna debido a que no existía en ese momento la presencia de colonos. Así los datos daban cuenta de una población pequeña, distribuida en 11 comunidades, 390 viviendas, 450 familias para un total de 3,405 habitantes (Diagnóstico TNC.1997). Seis años después, en noviembre del 2003, la organización de base del territorio, denominada MASAKU, hizo un nuevo autodiagnóstico que presentó a la Comisión Interinstitucional de Demarcación y Titulación (CIDT) y a la CONADETI, con el propósito de solicitar el proceso de demarcación y titulación del territorio conforme a la Ley 445. Este autodiagnóstico evidencia el crecimiento 
de la población mayangna en un $10 \%$ aproximadamente y la creación de cinco nuevas comunidades que totalizan entonces 16 comunidades, 538 casas, 746 familias para un total de 3,747 habitantes. En este período no se reporta la presencia de colonos en el TMSA y en el año 2005 es entregado el Título de propiedad colectivo en el marco de la Ley 445. En los años siguientes (2008 - 2009) se recuperan los bosques de la afectación del huracán Félix y ya en el año 2010, a partir del primer diagnóstico hecho por el GTI, es que se obtiene la primera información sobre la invasión de colonos.

\section{RESULTADOS DEL DIAGNOSTICO SOCIOECONÓMICO}

\section{Tamaño y composición de las familias de colonos}

Entre el periodo 2010 - 2014, el gobierno territorial indígena de este territorio (GTI TMSA) en coordinación con diversas instituciones de gobierno e instituciones no gubernamentales elaboró cinco diagnósticos sobre la invasión de colonos y un reporte (Betlehem), con el objetivo de analizar el fenómeno de la reciente inmigración. Complementariamente se cumplía con los requerimientos básicos para iniciar el proceso de saneamiento del territorio. Según los resultados de las encuestas realizadas a los colonos para la elaboración de estos diagnósticos queda claro que la invasión del territorio ha sido progresiva desde el año 2010. Únicamente durante el año 2011 se identifica un decrecimiento de este fenómeno, pero la tendencia de incremento ha continuado desde el año siguiente, 2012 (Véase el gráfico No. 2).

En promedio, en el periodo 2010 - 2012, la población de colonos pasó de 600 habitantes, que se encontraron en el año 2010, a 885 personas en el mes de julio del 2015, de las cuales 403 personas son del sexo femenino, representando el $45.5 \%$, y 482 personas son del sexo masculino, representando un $54.5 \%$. Cada familia puede estar compuesta aproximadamente por cuatro personas, no obstante, también es necesario hacer notar que algunas personas dijeron no tener familia, por lo que la composición familiar es variable y en algunos casos puede ser mayor o menor.

\section{¿Ya conocemos cuántos son? Ahora veremos de dónde vienen estas personas.}

Tal y como se puede apreciar en el cuadro No.1, estas personas provienen de distintos municipios de Nicaragua, siendo la mayoría de entrevistado procedentes u originarios de los municipios de las regiones autónomas (RACCN y RACCS), con un $71 \%$ en total.

\section{Gráfico No.2 Incremento poblacional en la invasión de colonos periodo 2010 - 2012}

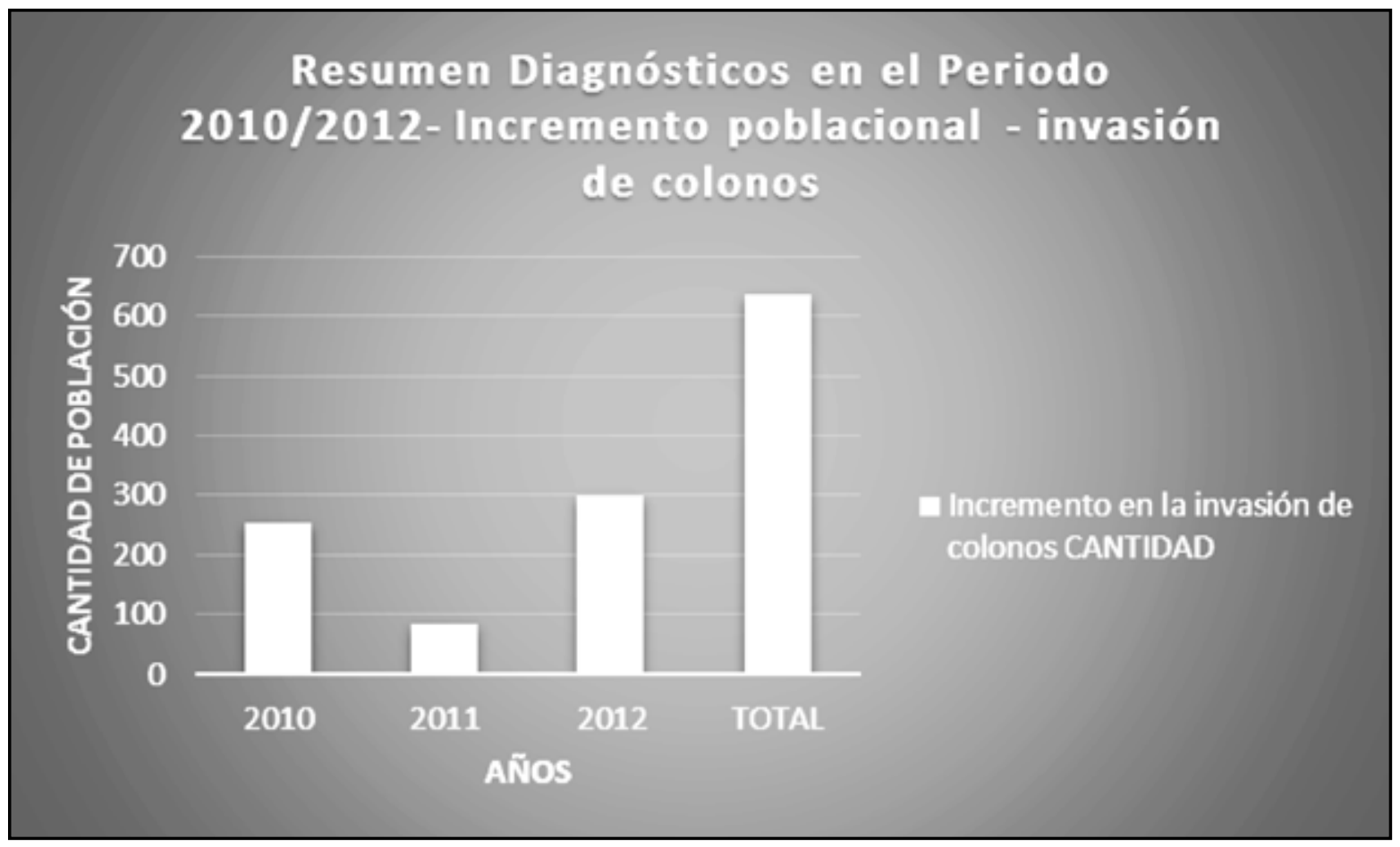

Fuente: Elaboración propia en base a los diagnósticos / Equipo consultor, julio 2015. 


\section{Cuadro No.1 Lugar de origen de los colonos invasores}

\begin{tabular}{|c|c|c|c|c|c|c|c|c|c|c|c|c|}
\hline \multirow{3}{*}{$\begin{array}{l}\text { Lugar de } \\
\text { origen }\end{array}$} & \multicolumn{10}{|c|}{ Sector } & & \\
\hline & \multicolumn{2}{|c|}{$\begin{array}{c}\text { 1.Palan Sahni } \\
\text { a Kauhmakwas } \\
\text { Sahni (mojón } 43 \\
\text { a 52) }\end{array}$} & \multicolumn{2}{|c|}{$\begin{array}{l}\text { 2. Kauhmakwas } \\
\text { Sahni a Kungh } \\
\text { Kungh Asang } \\
\text { (mojón } 52 \text { a 58) }\end{array}$} & \multicolumn{2}{|c|}{$\begin{array}{c}\text { 3.Kungh kungh } \\
\text { Asang a Kuru } \\
\text { Bahna (mojón } 58 \\
\text { a 64) }\end{array}$} & \multicolumn{2}{|c|}{$\begin{array}{c}\text { 4.Kuru Bahna a } \\
\text { Awas rau (mojón } \\
64 \text { hasta Awas } \\
\text { rau) }\end{array}$} & \multicolumn{2}{|c|}{ Sector 2 y 3} & \multicolumn{2}{|l|}{ Total } \\
\hline & Ocupantes & $\%$ & Ocupantes & $\%$ & Ocupantes & $\%$ & Ocupantes & $\%$ & Ocupantes & $\%$ & Ocupantes & $\%$ \\
\hline $\begin{array}{l}\text { Comunidad } \\
\text { Étnica }\end{array}$ & 1 & $4 \%$ & 13 & $22 \%$ & 12 & $35 \%$ & 1 & $50 \%$ & & & 27 & $14 \%$ \\
\hline $\begin{array}{l}\text { La Cruz de } \\
\text { Rio Grande }\end{array}$ & 8 & $30 \%$ & 2 & $3 \%$ & & & & & 13 & $17 \%$ & 23 & $12 \%$ \\
\hline Siuna & 1 & $4 \%$ & 2 & $3 \%$ & 1 & $3 \%$ & & & 13 & $17 \%$ & 17 & $9 \%$ \\
\hline Bonanza & & & 10 & $17 \%$ & 4 & $12 \%$ & 1 & $50 \%$ & 1 & $1 \%$ & 16 & $8 \%$ \\
\hline Chontales & & & 2 & $3 \%$ & & & & & 11 & $14 \%$ & 13 & $7 \%$ \\
\hline Tortuguero & 1 & $4 \%$ & & & & & & & 10 & $13 \%$ & 11 & $6 \%$ \\
\hline Rosita & 1 & $4 \%$ & 1 & $2 \%$ & 2 & $6 \%$ & & & 6 & $8 \%$ & 10 & $5 \%$ \\
\hline El Ayote & 4 & $15 \%$ & 2 & $3 \%$ & & & & & 2 & $3 \%$ & 8 & $4 \%$ \\
\hline $\begin{array}{l}\text { San Pedro del } \\
\text { Norte }\end{array}$ & 3 & $11 \%$ & & & & & & & 3 & $4 \%$ & 6 & $3 \%$ \\
\hline $\begin{array}{l}\text { Bocana de } \\
\text { Paiwas }\end{array}$ & 1 & $4 \%$ & 1 & $2 \%$ & 2 & $6 \%$ & & & 1 & $1 \%$ & 5 & $3 \%$ \\
\hline Rama & 2 & $7 \%$ & 2 & $3 \%$ & & & & & 1 & $1 \%$ & 5 & $3 \%$ \\
\hline Rio Blanco & & & 3 & $5 \%$ & 2 & $6 \%$ & & & & & 5 & $3 \%$ \\
\hline Matiguás & & & 1 & $2 \%$ & 1 & $3 \%$ & & & 2 & $3 \%$ & 4 & $2 \%$ \\
\hline Mulukukú & & & 3 & $5 \%$ & 1 & $3 \%$ & & & & & 4 & $2 \%$ \\
\hline $\begin{array}{l}\text { Alamikam- } \\
\text { bang }\end{array}$ & & & & & & & & & 3 & $4 \%$ & 3 & $2 \%$ \\
\hline El Tortuguero & 2 & $7 \%$ & & & & & & & 1 & $1 \%$ & 3 & $2 \%$ \\
\hline La Libertad & & & 2 & $3 \%$ & 1 & $3 \%$ & & & & & 3 & $2 \%$ \\
\hline Matagalpa & & & 2 & $3 \%$ & 1 & $3 \%$ & & & & & 3 & $2 \%$ \\
\hline Camoapa & 1 & $4 \%$ & & & & & & & 1 & $1 \%$ & 2 & $1 \%$ \\
\hline Nueva Guinea & & & & & & & & & 2 & $3 \%$ & 2 & $1 \%$ \\
\hline Prinzapolka & 1 & $4 \%$ & 1 & $2 \%$ & & & & & & & 2 & $1 \%$ \\
\hline San Carlos & & & 2 & $3 \%$ & & & & & & & 2 & $1 \%$ \\
\hline Biltingica & & & & & & & & & 1 & $1 \%$ & 1 & $1 \%$ \\
\hline Blufields & & & & & & & & & 1 & $1 \%$ & 1 & $1 \%$ \\
\hline $\begin{array}{l}\text { Comunidad } \\
\text { Indígena }\end{array}$ & & & 1 & $2 \%$ & & & & & & & 1 & $1 \%$ \\
\hline $\begin{array}{l}\text { Laguna de } \\
\text { Perla }\end{array}$ & & & & & & & & & 1 & $1 \%$ & 1 & $1 \%$ \\
\hline $\begin{array}{l}\text { Muelle de los } \\
\text { bueyes }\end{array}$ & & & & & & & & & 1 & $1 \%$ & 1 & $1 \%$ \\
\hline $\begin{array}{l}\text { Puerto Ca- } \\
\text { beza }\end{array}$ & & & & & & & & & 1 & $1 \%$ & 1 & $1 \%$ \\
\hline Waslala & & & 1 & $2 \%$ & & & & & & & 1 & $1 \%$ \\
\hline $\mathrm{n} / \mathrm{r}$ & 1 & $4 \%$ & 7 & $12 \%$ & 7 & $21 \%$ & & & 1 & $1 \%$ & 16 & $8 \%$ \\
\hline Total & 27 & $100 \%$ & 58 & $100 \%$ & 34 & $100 \%$ & 2 & $100 \%$ & 76 & $100 \%$ & 197 & $100 \%$ \\
\hline
\end{tabular}

Fuente: Elaboración propia / Equipo consultor. Encuesta Junio- Julio 2015. 
Los ocupantes originarios de la RACCS representan el mayor porcentaje con un $48 \%$, y destacan los municipios de La Cruz de Río Grande (12\%), El Tortuguero (8\%) y Bocana de Paiwas (6\%). La RACCN tiene por su parte el $30 \%$ de encuestados, con procedencia principalmente de Siuna (9\%), Bonanza (8\%) y Rosita (5\%). Los demás entrevistados, un 29\%, provienen de diferentes lugares; en el caso de Chontales que tradicionalmente ha sido referido por ser el lugar de origen de los migrantes con fines agrícolas - ganaderos en las regiones autónomas-, solo el $12 \%$ refirió ser originario de este Departamento. Un 9\% dijo ser proveniente de Matagalpa y un $8 \%$ no dio ninguna respuesta a la pregunta.

Esta información es interesante por sí misma, ya que evidencia que la ocupación de colonos, no proviene de las regiones del Pacífico a las que estamos acostumbrados a encontrar, sino que en un $71 \%$ en el TMSA, responde a una dinámica propia de migraciones con fines agrícolas - ganaderos y comercio de tierras, aunado a actividades ilícitas, a lo interno de las regiones autónomas. Este es el caso de la población que llega desde municipios del centro de la RACCS, que tienen al menos dos generaciones de pobladores que llegaron, en su momento, del Departamento de Chontales. Las migraciones desde la RACCS podrían deberse al desarrollo de proyectos de gran infraestructura en esta región, que para llevarse a cabo requieren de la compra de tierras que pertenecen a los campesinos, como lo es el caso del proyecto de la presa Tumarín, en La Cruz de Río Grande, lo cual finalmente desemboca en la creación de una clase social campesina con dinero pero sin tierras que se ve obligada a buscar nuevos destinos. Refiriendo la comunidad Tumarín, en el municipio de La Cruz de Río Grande, es necesario señalar que existen dos comunidades y se diferencian por ser Tumarín indígena (de origen miskito aculturizados españoles) y la otra Tumarín mestiza.

No obstante, en el caso de la RACCN, el panorama cambia mucho ya que la mayor parte de colonos proceden de municipios del triángulo minero, donde no se está realizando ningún proyecto de gran infraestructura y por lo tanto no existe la necesidad de buscar nuevas tierras. Se trata de pobladores que hace al menos tres años tenían sus propias tierras en estos municipios, de tal forma que nos encontramos frente un nuevo fenómeno de colonización campesina inmediata a la zona colonizada. Habría de estudiarse con mayor detalle las razones que llevan a estos colonos, originarios del triángulo minero, a ocupar las tierras del TMSA, ya que en este caso en especial el problema no necesariamente se trata de un colono sin tierra, sino que pueden ser más bien motivaciones económicas de grandes finqueros o inversionistas, por llamarles de alguna manera, que tienen dentro de su planificación la explotación irracional de los recursos naturales en la reserva de BOSAWAS.

\section{Cómo viven estos colonos en el TMSA. Infraestructuras y viviendas}

Tradicionalmente las viviendas de las comunidades mayangnas son hechas de madera y bambú, muchas de las cuales tienen techos de palma y/o zinc. En el TMSA, las casas de los comunitarios mayangnas se encuentran casi siempre distanciadas, cada cincuenta o cien metros, y se ubican a la orilla de los ríos Pis pis y Waspuk. Generalmente, los cultivos se desarrollan en el área destinada para uso agrícola que se ubica a diez o quince kilómetros de distancia de las comunidades, siempre a lo largo de la ribera de los ríos y con una penetración a lo interno del territorio no mayor a cinco kilómetros.

En el caso de los colonos, las viviendas forman parte integrante de las fincas y cuando tienen pensado establecerse la cercan con alambres, lo que delimita su accionar y se trata casi siempre de casas rústicas y ranchos con techos de palma. Del total de personas encuestadas, 92 dijeron vivir en casas rústicas y 87 refirieron vivir en ranchos, un pequeño número de encuestado dijo ocupar otro tipo de viviendas, $\mathrm{y}$, por último, 16 no respondieron.

\section{Situación de Educación}

El TMSA posee escuela primaria, multigrado y secundaria completa, con sede en la comunidad de Musawas, la comunidad principal del territorio. En el caso de las comunidades pequeñas del territorio se cuenta con escuelas multigrado. Ninguna de estas escuelas es visitada por niños o niñas hijas o hijos de colonos (Dx. TNC 1997 y MASAKU, 2003).

Los resultados de la encuesta evidencian que la mayor parte de la población de colonos adulta no terminó la educación primaria o es analfabeta. Del total de personas referidas en la encuesta, 258 son analfabetas y 137 tienen estudios primarios. En cuanto a la educación de los niños se hace mención de 23 personas, de los cuales el $42 \%$ son varones y $58 \%$ son estudiantes mujeres. No existe presencia -infraestructura- de escuelas primarias o secundarias en los sectores ocupados por los colonos, por lo cual se cree que los estudiantes viajan a zonas cercanas del municipio de Bonanza para estudiar. Muchos de los colonos tienen por prioridad el trabajo en la agricultura y en ocasiones se trata de cuidadores de fincas de otros colonos, de ahí que el nivel de escolaridad sea muy bajo. Estas familias viven 


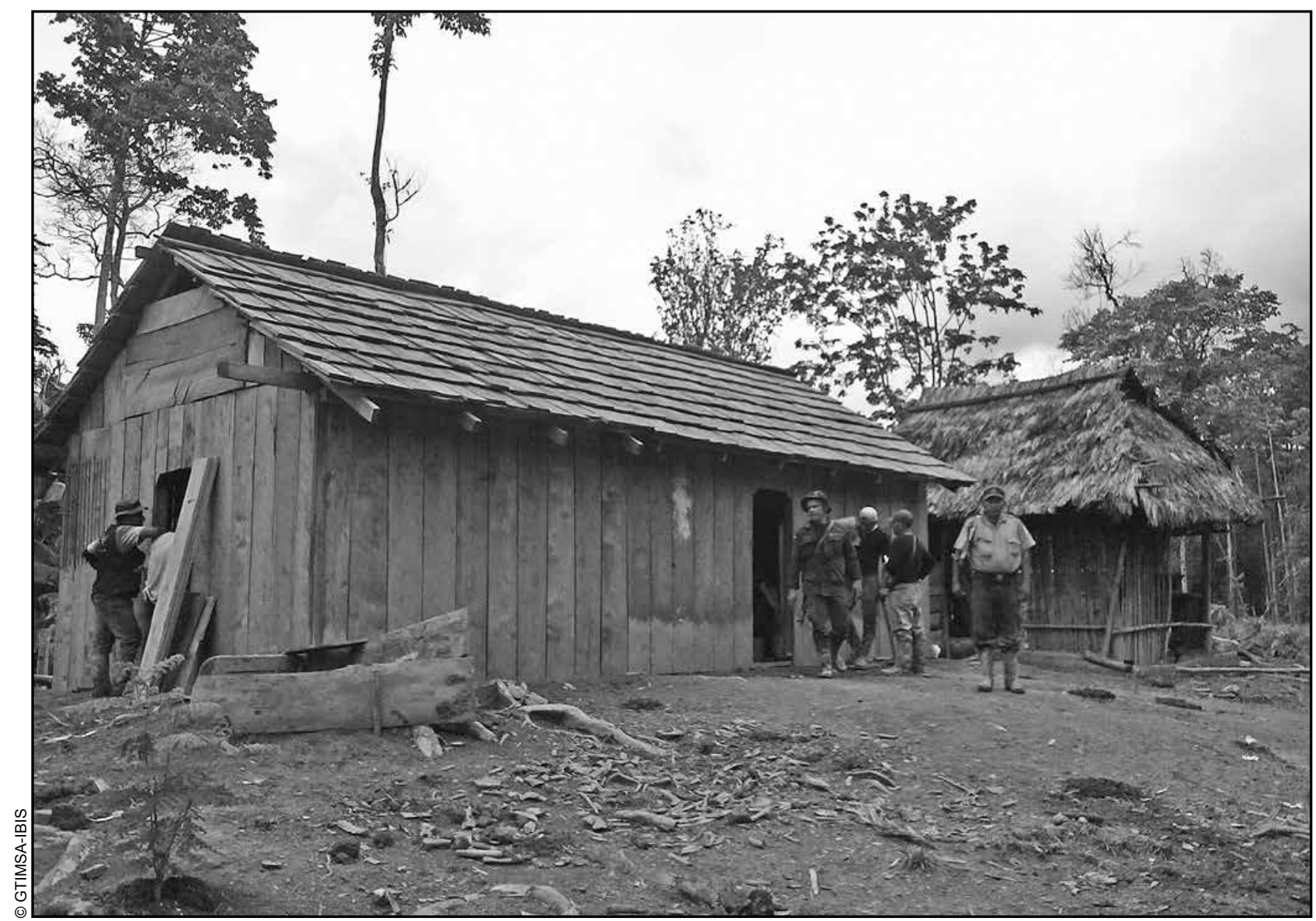

Fotografia tomada por el equipo encuestador durante el recorrido del trabajo de campo en los sectores visitados.

muy dispersas, con distancias mayores a dos kilómetros, su permanencia en el territorio es ilegal y no existe un censo adecuado que permita conocer la necesidad de educación.

\section{Situación de servicios de Salud}

La población de colonos en el TMSA recibe atención médica mediante la visita regular de enfermeras, brigadas de salud y médico general. La mayoría de ocupantes mencionaron que reciben el servicio de salud de esta forma. Sin embargo, existe un importante número de encuestados que no respondió. Cabe señalar que es una preocupación constante, para la población indígena mayangna que habita en el territorio, que la necesidad de atención médica y de educación de los colonos desemboque en la presencia institucional permanente del Ministerio de Educación y el Ministerio de Salud en estas zonas, ya que podría ser interpretado por los colonos como apoyo y consentimiento tácito, por parte de las instituciones públicas, para su permanencia en el TMSA. Sin embargo se hace necesario mencionar que las instituciones (Ministerio de Salud y Ministerio de Educación) actúan en estos lugares y atienden a la población con fines propiamente humanitarios ya que se sabe que la población requiere atención en salud y educación, y ésta es recibida con relativa periodicidad.

\section{Agua y Saneamiento}

Las cuencas hidrográficas del territorio MSA sirven de fuente de este recurso hídrico para los colonos. El 76\% de los entrevistados mencionó que la fuente principal de abastecimiento de agua para el consumo humano y para suplir sus necesidades básicas del hogar, es el río o quebradas, siendo los mayormente utilizados el río Wawa y Pispis, también existen pequeños afluentes del río Pispis. Solo 17 personas señalaron extraer agua de pozos, lo cual ya plantea la necesidad del colono y su familia para crear condiciones en sus viviendas, posiblemente porque tienen mayor interés de permanencia, nótese que en estos casos casi todas las familias ocupan tierras en los sectores 2 y 3 .

En cuanto al uso de servicio higiénico, la mayoría no utiliza letrinas y lo hace al aire libre, solamente un 14\% afirmó que sí la tenían y la utilizaban. Por lo tanto se 


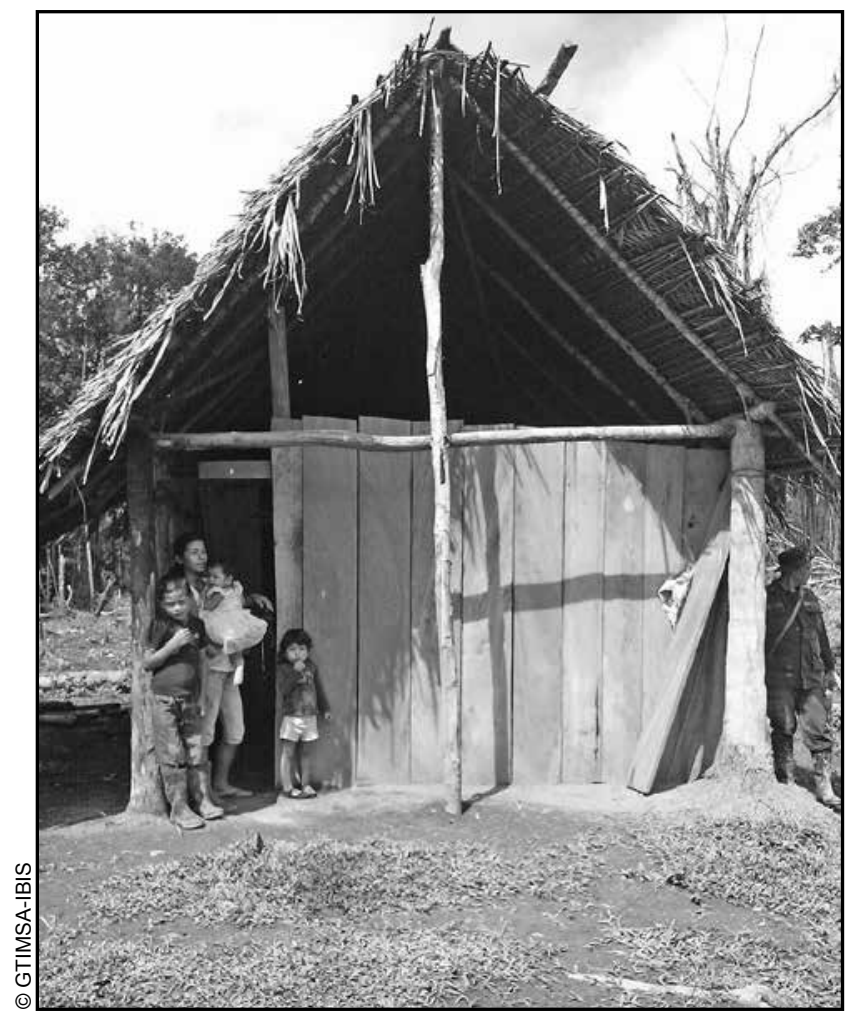

Fotografia tomada por el equipo encuestador durante el recorrido del trabajo de campo en los sectores visitados.

presenta una situación bastante particular en la cual de los 197 encuestados 96 dijeron no tener letrinas en sus casas. Esto plantea tres situaciones posibles: la primera es que el $48.73 \%$ de los encuestados y sus familias defecan al aire libre, la segunda situación es que aunado a las mínimas condiciones de las casas que los colonos construyen se podría tratar de una población que no necesariamente reside de forma permanente en estas viviendas y la tercera situación posible es que se trata de cuidadores de fincas de campesinos o colonizadores de tierras que viven en ciudades cercanas, como las cabeceras de los municipios del triángulo minero. Obsérvese que todas las 27 personas que señalan tener letrinas viven en el sector 2 y 3 y se denota que ésta es el área con mayor densidad poblacional. Del total de las personas que ocupan tierras en los sectores 1 y 4 ninguno tiene letrina. Cuando se les preguntó sobre qué hacían con la basura, un $60 \%$ contestó que la tiran y no hacen nada más con ella, mientras un $15 \%$ la quema, un $4 \%$ la entierra y un $21 \%$ no contestó.

\section{La actividad económica a la que se dedican los colonos invasores entrevistados}

La mayoría de los encuestados dice que su principal actividad económica es la agricultura. En cada uno de los sectores seleccionados para realizar la encuesta, la actividad principal es siempre la agricultura; así, por ejemplo, en el sector 1 se trata del $63 \%$, en el sector 2 es el $77 \%$, en el sector 3 el $88 \%$, y en el sector 4 el 100\% de los encuestados se dedica a la agricultura. Esta fue la actividad que los colonos señalaron como principal fuente de ingreso económico de sus familias y para desarrollarla utilizan entre 50 y 300 manzanas. Según los resultados del estudio, estas 197 familias ocupan un área de 17,636 manzanas, siendo los sectores más afectados el 2 y 3 con un porcentaje de $88.30 \%$ de las manzanas ocupadas por colonos. Esta práctica de uso de tierras por familia es contraria a la práctica del pueblo mayangna, que no suele asignar grandes proporciones de tierra a una sola familia para dedicarse a la agricultura en tierras que son eminentemente de vocación forestal.

En el TMSA normalmente los mayangnas se asignan alrededor de tres a cuatro manzanas por familia, ya que la práctica cultural es sembrar y cosechar para el auto consumo. Cada año se va cambiando el lugar de las parcelas, de tal forma que se deja descansar la tierra por espacio de dos a tres años. Una vez que la tierra se ha recuperado inicia el crecimiento de tacotales que en esta zona de la reserva de BOSAWAS se caracteriza por plantas que sirven para abono. De ahí que la práctica agrícola de los colonos es contraria e incompatible con los usos que habitualmente se les ha dado a las tierras en el TMSA.

Pese a que en las tierras ocupadas por los colonos se ven las grandes fincas y por consiguiente el despale del bosque, no se encontró grandes sembrados por lo cual se desconoce sobre el tipo de cultivos que se siembran en los cuatro sectores y tampoco se maneja que estos cultivos sean vendidos en alguna ciudad aledaña. Se sabe que la práctica agrícola campesina es preparar grandes extensiones de tierra para sembrar a gran escala y dedicar parte de la cosecha al comercio. También se conoce de este tipo de prácticas que, una vez levantada la cosecha, se deja crecer pastizales para el ganado. Sin embargo, y haciendo referencia a la ganadería, no se encontró evidencia que los colonos manejen grandes pastizales para ganado, por lo cual esta actividad también tiene poco sustento.

Ahora bien, según el estudio de campo la ganadería ocupa el segundo lugar en las actividades económicas de las familias de colonos en porcentajes bastante mínimos. En el sector 1, el 25\% de los colonos se dedica a esta actividad, en el sector 2 se trata del 18\%, en el sector 3 se hace referencia al 7\% y en el sector 4 no existen personas que trabajan en la ganadería. Existen otras actividades desarrolladas por los colonos pero con un menor número 
de participación, aunque evidencian claramente el uso irracional de los recursos sujetos a conservación en la reserva de BOSAWAS.

Al menos 18 personas refirieron dedicarse a la caza y pesca, las cuales no son prácticas habituales o sostenibles de los colonos. Es posible que estas actividades se empiezan a desarrollar en vista de que es muy común encontrar en el TMSA una diversidad muy rica de especies de animales exóticos, y a partir de ahí surge el interés de los colonos para dedicarse a estas actividades. Esto suscita una preocupación, puesto que no se conoce el fin económico de esta actividad o el mercado, de tal forma que se puede dejar planteado ya que los colonos que desarrollan estas actividades sin conocimientos de los usos del suelo, según las normas del territorio MSA, están poniendo en riesgo el equilibrio y el hábitat de las especies en las áreas que ocupan en el territorio y que están protegidas en la reserva de BOSAWAS.

Además cabe señalar que los colonos cuentan con sus pequeñas tiendas o pulperías, abastecidas regularmente y que hacen indicar la capacidad adquisitiva de estos ocupantes, ya que para llevar los productos de abastecimiento hasta los sectores 1, 2, 3 y 4 se requiere siempre transporte terrestre o bestias de carga. Según los reportes de los informes de campo de los encuestadores, los colonos tienen sus propias bestias y manejan bien abastecidas sus tiendas. Para finalizar esta sección, los colonos también señalan dedicarse en menor número a la güirisería, que en estos sectores se práctica de forma artesanal mediante el lavado en los ríos. Este recurso poco explotado aún por los colonos podría ser un foco que genere nuevas migraciones de colonos interesados en incursionar en la actividad económica más lucrativa del municipio de Bonanza, lo cual también supone un daño ambiental por el uso de mercurio para el lavado del oro en los ríos de MSA.

\section{Tipología de Productores}

Cabe mencionar que no existe un estudio a profundidad en este tema ni para El TMSA ni para la reserva BOSAWAS, pero sí se puede hacer una aproximación y mencionar los tipos de productores más importantes que se aprecian en el territorio actualmente.

En su mayoría son campesinos - sin tierra- y dentro de éstos se pueden clasificar en: campesinos sin tierra (real) que aprovechan la oportunidad (precios de la tierra bajos, promesas electorales, permisos sin validez extendidos por políticos, etcétera) que se les presenta para hacerse de un área de convivencia y trabajo para su familia; otros que han perdido sus tierras en sus lugares de origen ya sea por acciones antrópicas (embargos, robos, asesinatos, expropiación por empresas extranjeras, etcétera) o evento natural (continuamente afectados por huracanes por ejemplo).

Campesinos sin tierra pero que han convertido esto en negocio (traficantes de tierras). Éstos inicialmente comienzan como campesinos sin tierra (real) para luego en el proceso convertirse en delincuentes, traficando tierras sin ningún asidero legal, pero eso sí, acompañado de toda una red de apoyo (llámense autoridades locales y municipales, en algunos casos los propios comunitarios indígenas (malos hijos del territorio que se venden), abogados, políticos, etcétera).

Campesino sin tierra (peones) que trabajan para un hacendado -terrateniente local o foráneo. Es el típico enviado para hacer posesión de tierras, con el objetivo primero de descombrar y vender la madera para luego meter pastos y ganado y posteriormente comercializar las mejoras y seguir avanzando.

Ex militares -desmovilizados convertidos en campesinos a la fuerza. Según este grupo, la tierra ocupada, y en donde están tratando de asentarse, son tierras baldías y están localizadas principalmente en la zona del TMSA llamada El Tesoro. Cabe señalar que este es el grupo de colonos más difícil y conflictivo, de los que se encuentra en el territorio, a la hora de negociar, ya que no acepta ningún diálogo y amenaza con levantarse en armas teniendo como consecuencia la violencia que genera muertes tal y como ha sucedido anteriormente en la Reserva.

\section{ASPECTOS SOCIO AMBIENTALES}

\section{Uso histórico y actual del suelo}

El área que comprende el TMSA ha sido históricamente ocupada por comunidades de la etnia mayangna, las cuales por tradición han hecho un uso racional de los recursos naturales, tal y como lo muestra la zonificación ecológica y económica aprobada en el 2011 por la Asamblea de líderes tradicionales indígenas y miembros del GTI TMSA. Ese uso tradicional y racional de los recursos naturales característico de las comunidades indígenas del Caribe nicaragüense -con un fuerte componente de conservación- fue una de las razones principales por las cuales el Estado Nacional creó la Reserva Natural BOSAWAS, que posteriormente pasó a ser patrimonio de la humanidad, a través de la definición de este territorio como Reserva de Biosfera por la UNESCO en el año 1997. 


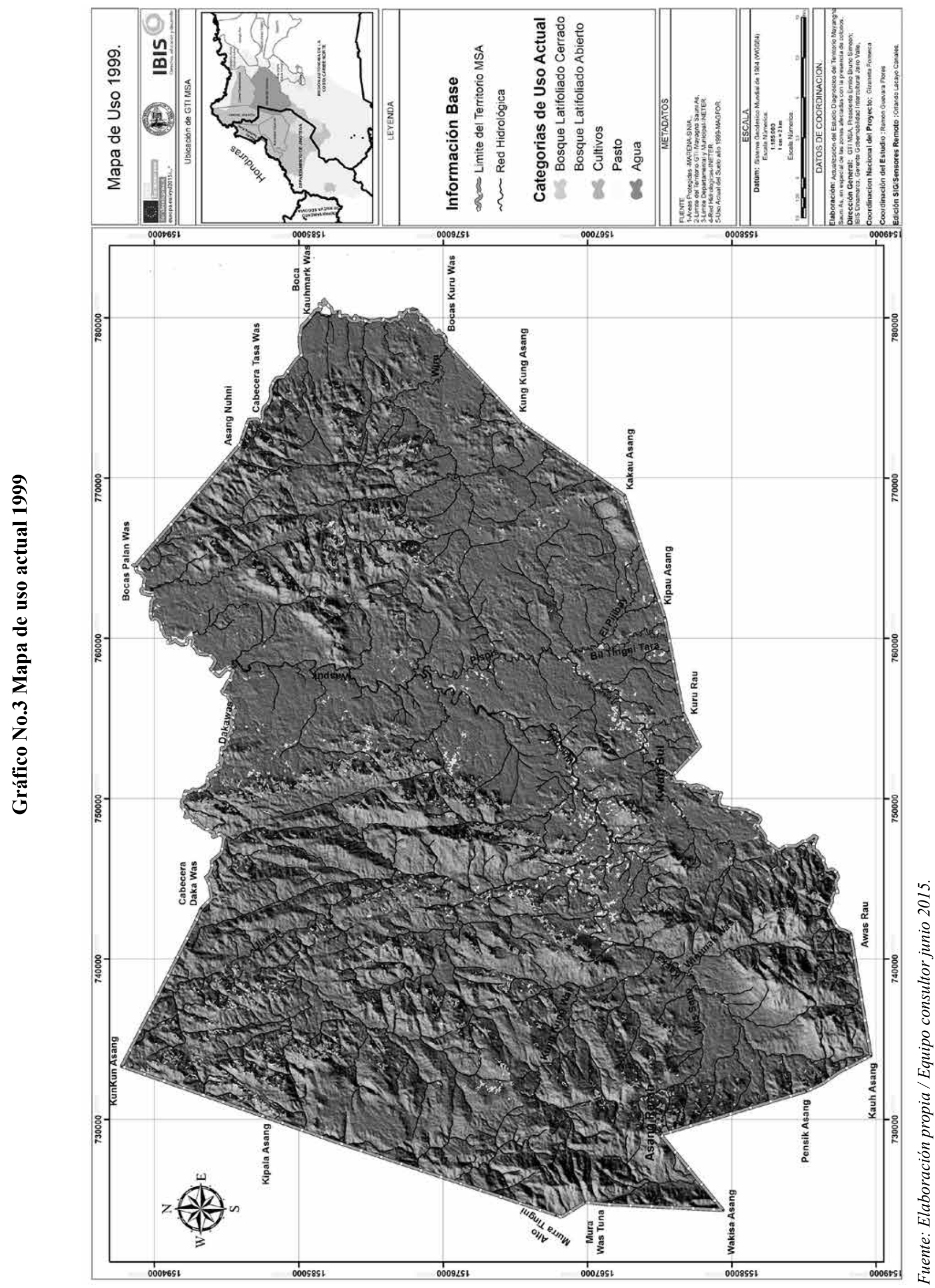


El mapa muestra que las áreas de bosque latifoliado, cerrado en el año 1999, representaban más del 95\% del territorio MSA, pese a que las familias mayangnas utilizan áreas para sembrar arroz, tubérculos y musáceas, entre otros cultivos, así como para realizar sus actividades de caza, pesca y güirisería tradicional. En contraste con el uso de suelo de los campesinos mestizos que están ocupando el territorio de manera ilegal, ya que un alto porcentaje de las áreas que utilizan se orienta al uso agropecuario con pocas áreas de conservación del bosque primario. Esto se ve claramente en mapas posteriores al paso del huracán Félix en el año 2007. En este sentido es importante mencionar que el huracán Félix fue un evento catastrófico que afectó significativamente el estado de los bosques tanto en la zona núcleo como en la zona de amortiguamiento de BOSAWAS y, muy particularmente, en el TMSA, como lo muestra el siguiente mapa de afectación después del evento en el año 2008.

Existen estudios previos de bosques huracanados -como los realizados por la universidad de Michigan en el bosque afectado en 1988, por el huracán Juana en la RACCSlos cuales refieren que los bosques tienen la capacidad de regeneración rápida, siempre y cuando el banco de semillas en el suelo no se vea afectado por fuego u otras actividades humanas. En el caso del TMSA, el bosque tumbado propició una creciente ocupación ilegal de este territorio, facilitando que familias campesinas pudieran tener acceso rápido a áreas de cultivo, antes cubiertas por bosque primario, tal y como se ve en el mapa de uso del suelo del año 2010. Este resultado es consecuente con los diagnósticos jurídicos realizados por el GTI a partir de este año (ver sección en el apartado socioeconómico):

El mapa anterior muestra claramente que el principal frente de invasión de colonos mestizos ha sido en los sectores 2 y 3. También se muestra que tanto en los sectores 1 y 2 , como en la zona núcleo de BOSAWAS (al norte del sector 4) el bosque se venía restaurando de forma rápida después de tres años del paso del huracán. Sin embargo, en la actualidad, con el presente diagnóstico (apoyado por imágenes de satélite de enero de 2015 y las verificaciones de campo) se reconstruyó el mapa de uso actual del suelo del corriente año. En el mismo podemos ver que continúa el cambio paulatino de reconversión de áreas de bosque cerrado y abierto a áreas de cultivo, pastos y tacotales; documentado en los diagnósticos jurídicos a partir del 2010 (comparar mapas 2010-2015).

\section{Gráfico No.4 Mapa de uso actual 2008}

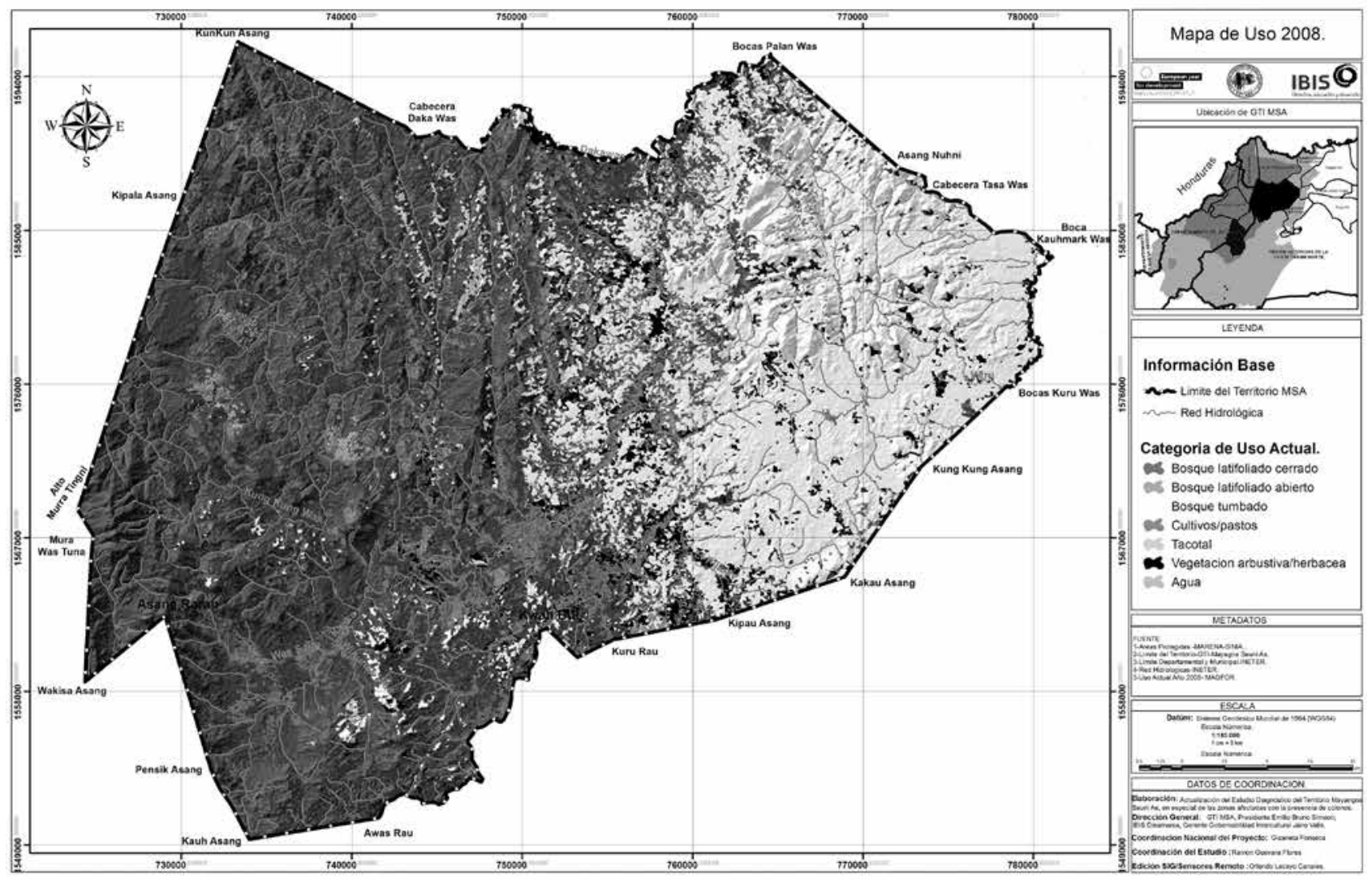

Fuente: Elaboración propia / Equipo consultor junio 2015. 
Gráfico No.5 Mapa de uso actual 2010

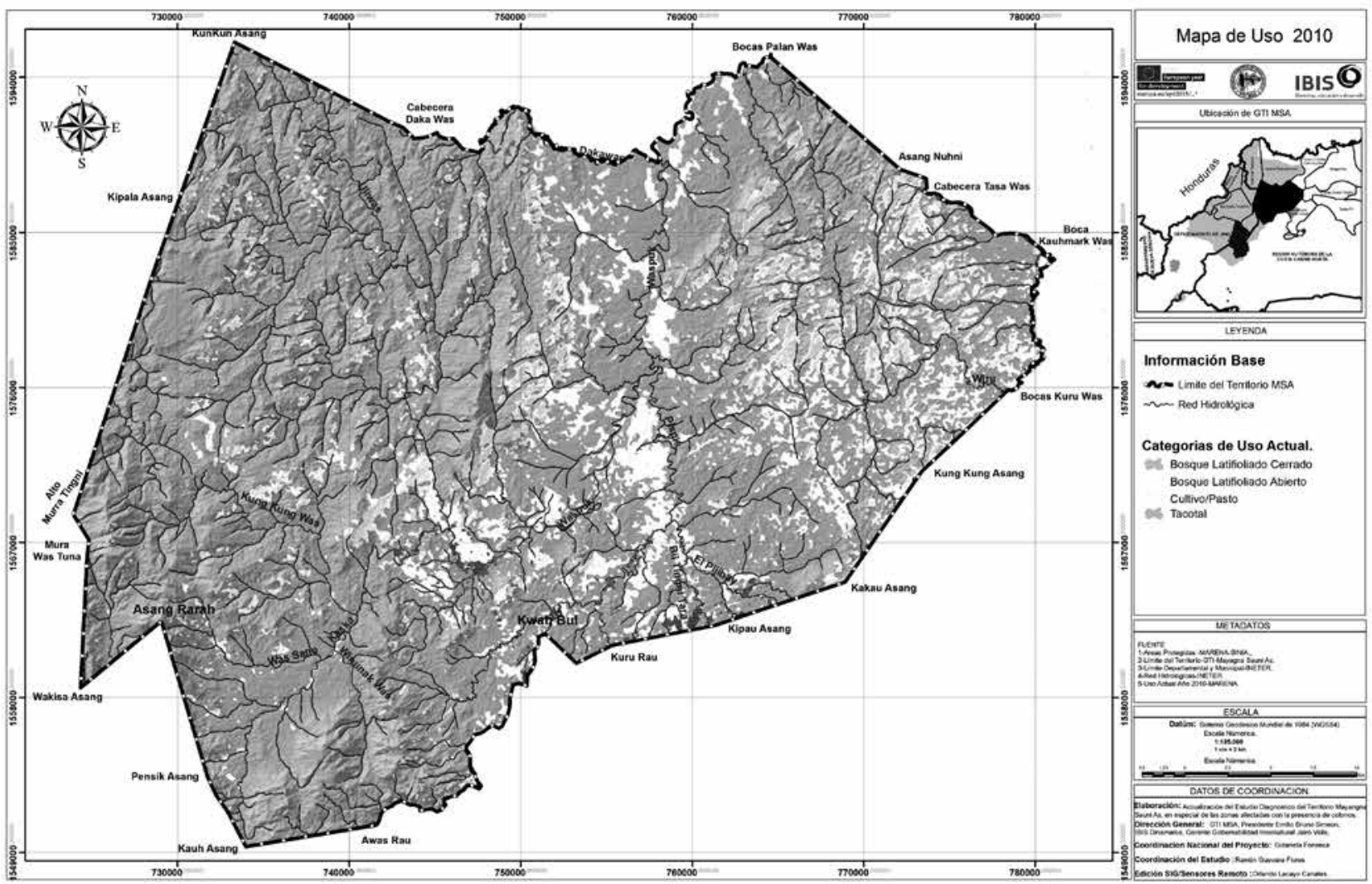

Fuente: Elaboración propia / Equipo consultor junio 2015.

Gráfico No.6 Mapa de uso actual 2015

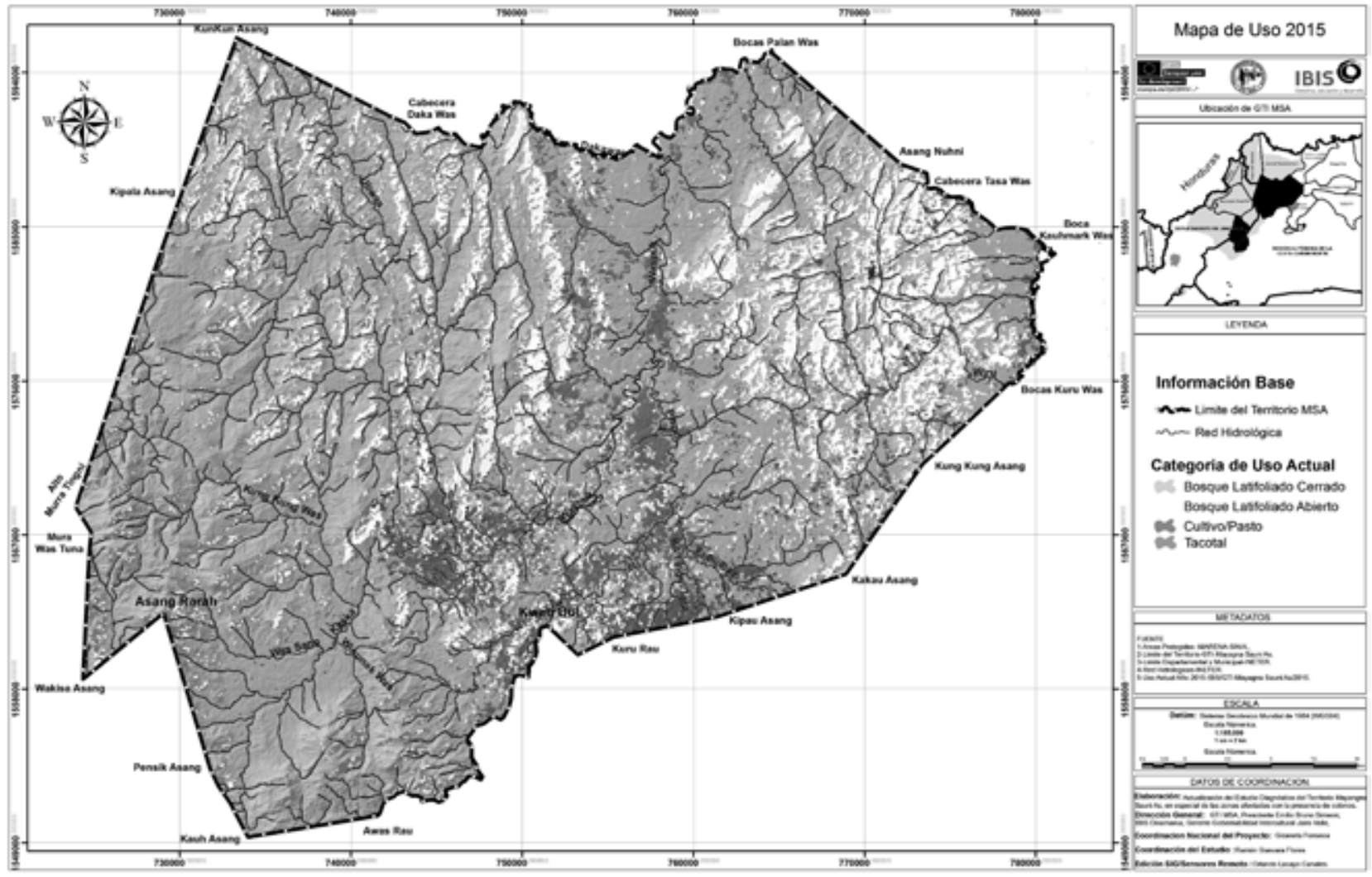

Fuente: Elaboración propia / Equipo consultor junio 2015. 
El mapa también muestra que se ha incrementado la presencia de invasores en los sectores 1 y 2 , como se pudo comprobar en las rutas realizadas para encuestar a los ocupantes ilegales. Es importante mencionar que en estos dos últimos sectores se detectó una serie de caminos de acceso reciente, que utilizan los colonos para ocupar más áreas de tierra lo cual es un foco potencial de conflicto a mediano plazo (en el informe completo se puede encontrar los puntos geo referenciados de la ubicación de fincas encuestadas y los caminos de acceso, en la sección sobre la situación jurídico legal de los colonos).

En conclusión, la invasión de colonos ha sido sostenida desde el diagnóstico legal realizado por el GTI en el año 2012, hasta el presente diagnóstico actualizado con la última incursión de campo del equipo consultor en julio del 2015. Por consiguiente, la afectación en el uso del suelo del territorio ocupado por colonos es severa. Y esta afectación se ve directamente reflejada en la deforestación del bosque, la pérdida de biodiversidad y la contaminación de las aguas por sedimentación y por uso de agroquímicos y pesticidas en la producción de granos básicos.

\section{Uso potencial del suelo}

En el caso del mapa de uso potencial del suelo del TMSA, sabemos que éste se basa en la vocación del suelo para actividades humanas productivas tal y como se muestra en la figura; y es por este uso potencial que tiene el suelo, que se presenta la problemática de invasión de colonos (más del 90\% del territorio tiene un uso potencial agropecuario). Sin embargo, cuando se habla de áreas protegidas dichas categorías de uso potencial no aplican en su totalidad, por el estatus especial de estas áreas para conservación de biodiversidad y uso racional de los recursos naturales. Por otro lado es importante recalcar que en el mapa aprobado en 2011 por el GTI y el liderazgo comunal del TMSA, la zonificación de usos ecológicos y económicos del territorio es compatible con las categorías de uso de la reserva de Biosfera de BOSAWAS.

Para los mayangnas la existencia de BOSAWAS se debe fundamentalmente al uso que ellos le dan a sus territorios históricos y que a partir del año 2005 han sido reconocidos por el Estado de Nicaragua a través de títulos de propiedad comunal. Es por esto que estas comunidades originales reafirman su papel como garantes de la conservación y uso sostenible de esta Reserva de Biosfera.

\section{Gráfico No.7 Mapa de uso potencial}

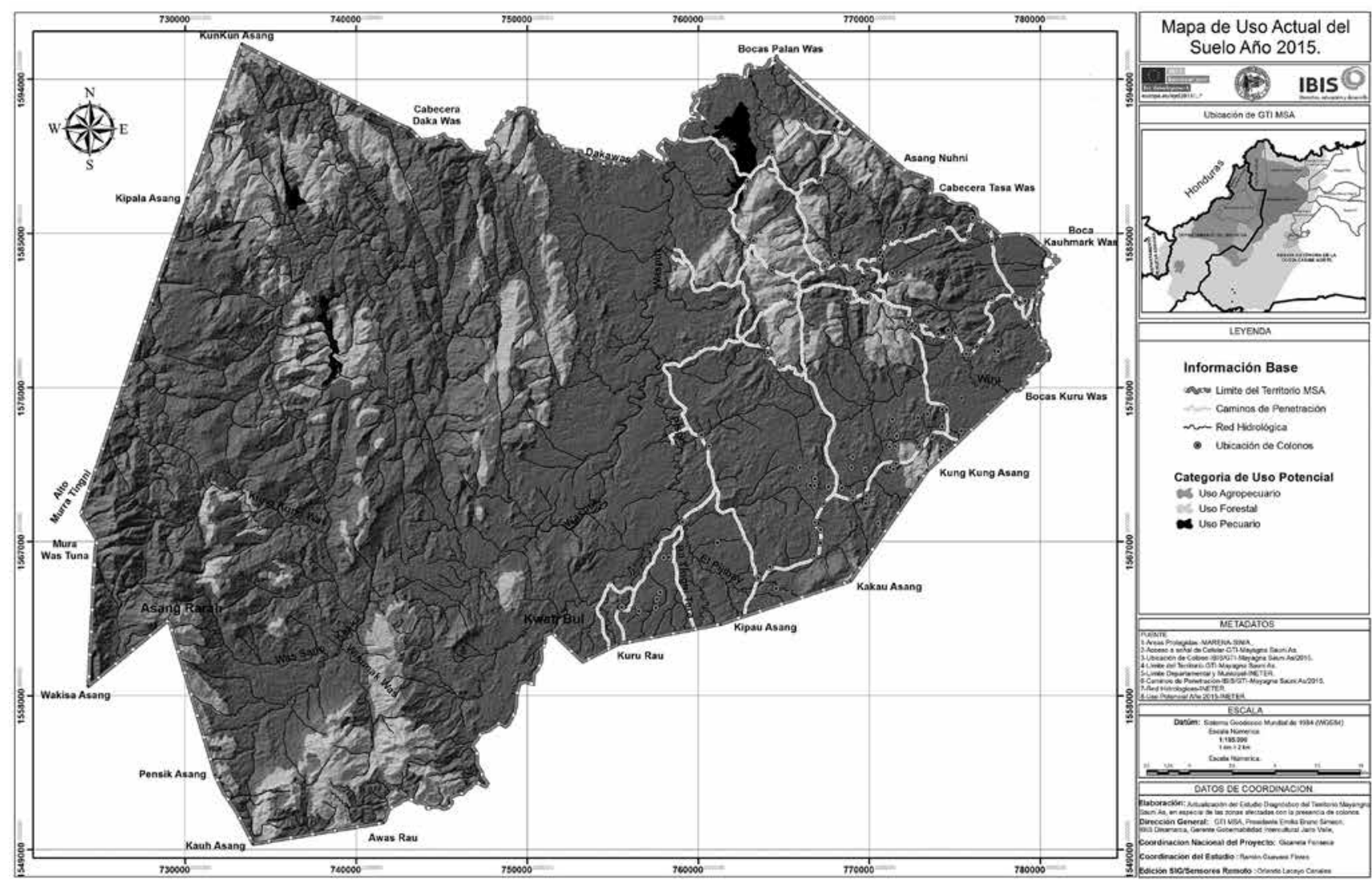

Fuente: Elaboración propia / Equipo consultor junio 2015. 


\section{Confrontación de usos e impactos socioambientales de las actividades de los colonos}

Tanto BOSAWAS como el TMSA tienen definidas categorías de uso que permiten ciertos tipos de actividades humanas en la zona de amortiguamiento y en la zona núcleo. Como hemos visto en los mapas de uso histórico y actual, la mayoría de las actividades agrícolas, y por consiguiente de impacto ambiental, realizadas por colonos en el TMSA han sido en la zona de amortiguamiento; esto independientemente del estatus legal en que se encuentran estos colonos, lo cual será discutido en un capítulo posterior de este artículo.

Si analizamos de manera contrapuestas el uso histórico del suelo de la población indígena y mestizas encontramos que los bosques se ven mayormente afectados por el uso que hace la población mestiza. La tendencia es clara hacia la pérdida de cobertura boscosa (cerrado y abierto), de casi $100 \%$ en 1999, a cerca de un $91 \%$ en la actualidad (2015), obviando los cambios temporales causados por el huracán Félix (2008).

Aunque en términos porcentuales estos cambios aparentan no ser significativos, en términos absolutos se han perdido cerca de 31,000 hectáreas de bosques primarios (cerrado) en este período (1999-2015), a un ritmo de 600 hectáreas por año a partir del 2010 hasta la fecha. De igual forma se ha aumentado en cerca de 18,000 hectáreas el bosque latifoliado abierto afectándose principalmente la diversidad biológica de este territorio, la cual es la base y sustento de las comunidades mayangnas. Sin embargo si hiciéramos un análisis únicamente de la parte del TMSA que corresponde a zona de amortiguamiento de BOSAWAS, vemos que la tasa de deforestación aumenta sustancialmente al ritmo de 1,115 ha/año para el mismo período 2010-2015. De continuarse con esta tendencia, en los próximos cinco años la deforestación alcanzaría niveles alarmantes en la zona de amortiguamiento, con amenazas serias a la zona núcleo de la Reserva.

Junto con este impacto directo en el bosque, producto de las actividades ganaderas principalmente, también están los impactos en la red hídrica, tales como sedimentación de caños y ríos navegables por la erosión de los suelos, así como por el uso de agroquímicos ahora bastante generalizado en las comunidades campesinas. Por ejemplo, si estimamos que las 197 familias de colonos presentes en el TMSA poseen entre dos y cinco frascos de herbicidas e insecticidas por familia, tenemos una proporción de entre 394 a 985 litros de químicos que parcialmente entran en las vertientes de los caños y que potencialmente afectan la fauna acuática y de la calidad de agua para consumo humano de esta red hídrica.

Asimismo, otro impacto importante producto de la presencia de colonos en el TMSA, aunque difícilmente medible en su magnitud en este momento por la naturaleza del presente estudio, es el impacto en la fauna terrestre. La caza es comúnmente practicada tanto por indígenas como por mestizos, aunque estos últimos la practican no solo para consumo de proteína silvestre, sino también con otros fines (mascotas, "protección" de su ganado, cacería deportiva, etc.). De igual forma, si estimamos que las 197 familias tienen entre tres y cinco perros de cazas, tenemos un total de entre 591 a 985 perros que amenazan fuertemente la fauna terrestre, principalmente mamíferos.

Adicionalmente a este análisis de localización de pérdida de la biodiversidad de fauna y del bosque primario, está documentado que el cambio en el uso del suelo, de bosques a actividades de agricultura y ganadería, es la principal causa de producción de gases de efecto de invernadero en Nicaragua. Esto redunda en la contribución del país y sus habitantes al cambio climático que está afectando a todo el planeta y que a su vez impacta principalmente a las poblaciones vulnerables de nuestro país (comunidades pobres campesinas e indígenas). En síntesis, los principales impactos socioambientales de la invasión de colonos al TMSA son la pérdida de la biodiversidad y de los servicios ambientales que proporciona el bosque, así como la contaminación de las aguas por sedimentación y por uso de agroquímicos y una contribución (aunque mínima, no se puede omitir) al cambio climático. Todo esto impacta en el corto, mediano y largo plazo a la calidad de vida de las comunidades mayangnas dueñas de este territorio. 
Cuadro No. 2 Resumen general de amenazas identificadas

\begin{tabular}{|c|c|c|}
\hline AMENAZAS & CAUSA - EFECTO & $\begin{array}{c}\text { ELEMENTOS DE } \\
\text { CONSERVACION AFECTADO }\end{array}$ \\
\hline $\begin{array}{l}\text { Tráfico ilegal de tierras - venta } \\
\text { de lotes sin documentos legales }\end{array}$ & $\begin{array}{l}\text { Deforestación en zonas de reserva, } \\
\text { comercialización de madera sin control, } \\
\text { inestabilidad social entre grupos poblacionales } \\
\text { (dueños del territorio - Invasores) }\end{array}$ & Bosque húmedo tropical \\
\hline Deforestación & $\begin{array}{l}\text { Avance de la frontera agrícola, áreas de } \\
\text { bosque destinadas a conservación y/o } \\
\text { protección de suelos y aguas son afectadas } \\
\text { para garantizar condiciones mínimas de } \\
\text { habitabilidad de la población campesina } \\
\text { (invasión de colonos), y por comercialización } \\
\text { indiscriminada de especies maderables que } \\
\text { incide en mayor fragmentación del hábitat. }\end{array}$ & $\begin{array}{l}\text { Bosque húmedo tropical, cambio de } \\
\text { uso del suelo, cuencas hidrográficas }\end{array}$ \\
\hline $\begin{array}{c}\text { Comercialización } \\
\text { indiscriminada de madera }\end{array}$ & $\begin{array}{l}\text { Avance de la frontera agrícola, fragmentación } \\
\text { del hábitat, disminución de caudales en ríos, } \\
\text { pérdidas de pequeños riachuelos y ojos de } \\
\text { agua, erosión en suelos }\end{array}$ & $\begin{array}{l}\text { Bosque húmedo tropical, cambio de } \\
\text { uso del suelo, cuencas hidrográficas }\end{array}$ \\
\hline $\begin{array}{c}\text { Técnicas inadecuadas } \\
\text { productivas en agricultura, } \\
\text { ganadería, forestería y minería. }\end{array}$ & $\begin{array}{l}\text { Una vez deforestado y comercializada } \\
\text { toda la madera se incorpora el ganado en } \\
\text { el territorio. Por lo que el uso indebido } \\
\text { y persistente de malas prácticas genera } \\
\text { baja rentabilidad y deterioro ambiental, } \\
\text { afectando los ecosistemas donde se realizan } \\
\text { estas actividades }\end{array}$ & $\begin{array}{l}\text {-Bosque húmedo tropical, suelos, } \\
\text { fauna }\end{array}$ \\
\hline Cacería sin control & $\begin{array}{l}\text { Cazadores furtivos dedicados a } \\
\text { comercialización de fauna, comunidades } \\
\text { que realizan caza de subsistencia, aumenta } \\
\text { peligrosamente la lista de especies en peligro } \\
\text { de extinción }\end{array}$ & $\begin{array}{c}\text { Fauna } \\
\text { incrementándose las especies en } \\
\text { peligro de extinción }\end{array}$ \\
\hline Avance de la frontera agrícola & $\begin{array}{l}\text { Sectores de campesinos sin tierras } \\
\text { provenientes de la región central del país } \\
\text { avanzan, sin ninguna planificación, sobre la } \\
\text { zona de Bosawas, constituyendo un peligro } \\
\text { socioeconómico por el potencial de conflicto } \\
\text { con los grupos indígenas, y por el deterioro } \\
\text { ambiental que causan debido a las prácticas } \\
\text { agropecuarias inadecuadas }\end{array}$ & $\begin{array}{l}\text { Cultura y tradiciones indígenas, } \\
\text { suelos y cuencas, bosques y fauna }\end{array}$ \\
\hline
\end{tabular}

Fuente: Adaptación hecha a la matriz presentada en el documento Bosawas informe técnico CBA y adaptada al TMSA. 


\section{ANÁLISIS JURÍDICO LEGAL DE LA SITUACIÓN DE LOS COLONOS}

El título fue inscrito en marzo del 2006 y a partir de este momento se crea el primer asiento registral sobre la propiedad del TMSA, dando lugar a la legalidad del derecho de propiedad comunal de este territorio. Se hace notar que el título otorga, a las comunidades del territorio MSA, total dominio sobre todas la zonificaciones con excepción de la zona de conservación sin explotación, debido a que se trata de la zona núcleo de la reserva de BOSAWAS y ésta se administra conforme al manejo conjunto de áreas protegidas con el MARENA. Según el título, esta área tiene una extensión de $705.11 \mathrm{~km}^{2}$, lo cual representa el $43.04 \%$ del total de territorio titulado.

Gráfico No. 8. Carátula del título de propiedad

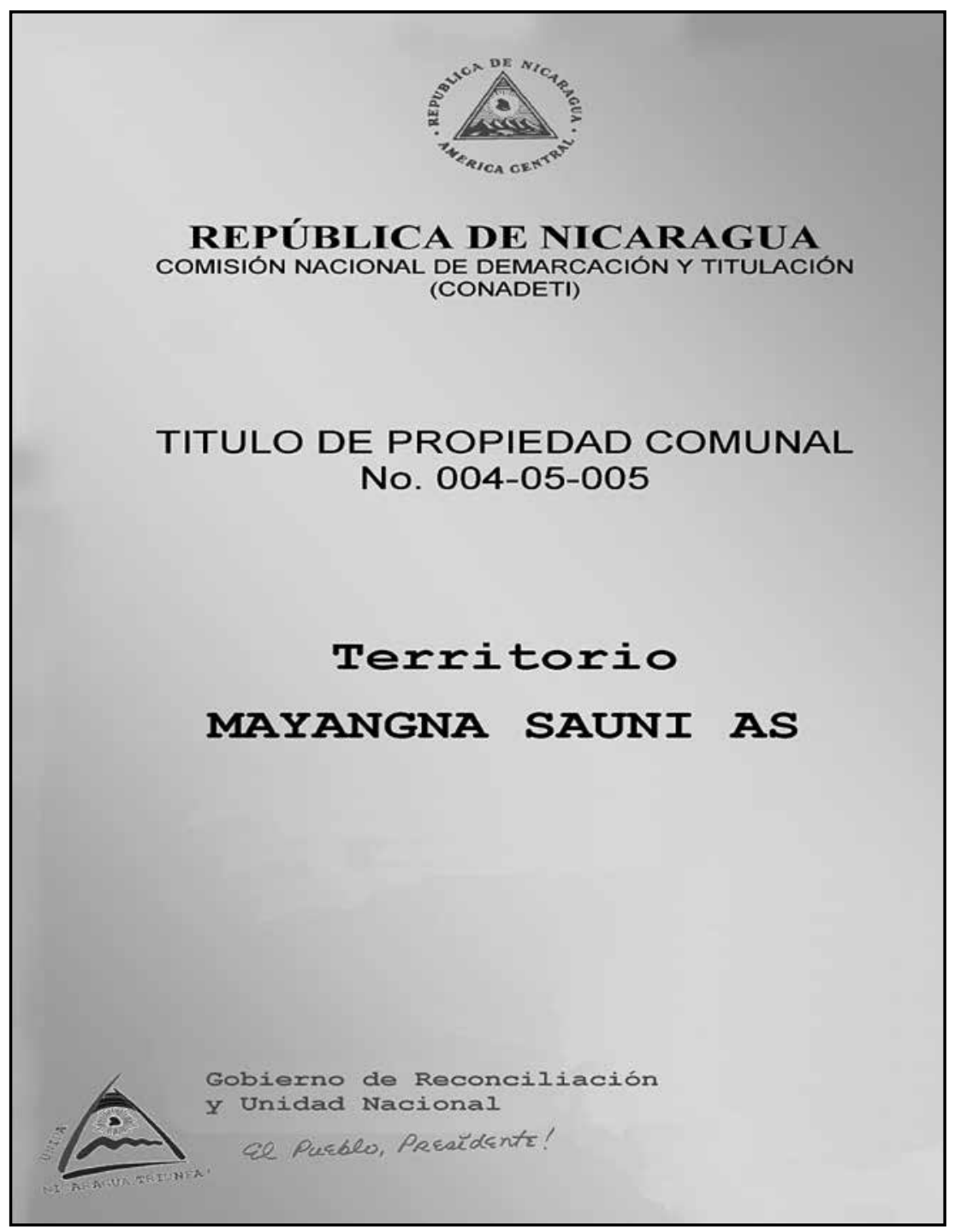

Este título se inscribió sin mayores retrasos debido a que no existía referencia previa de disputa legal con colonos u otros pueblos indígenas sobre el territorio titulado. Surge después la necesidad de realizar encuestas diagnósticas del territorio, a partir del año 2010, con la identificación de la migración progresiva de colonos, tarea que es realizada en conjunto por el GTI MSA y la CONADETI. Estos instrumentos de estudio tenían la finalidad de identificar a los colonos que ocupaban ilegalmente tierras en MSA post titulación, la ubicación de sus fincas y el porcentaje del territorio que ocupaban. No obstante, los estudios previos no se referían al efecto de la ocupación de colonos en el territorio, la modificación de la composición socioeconómica y su repercusión en el medio ambiente, la alteración de la dinámica jurídico-política del territorio, que obliga a las autoridades y comunitarios de MSA a defender su madre tierra y establecer nuevas relaciones interinstitucionales en función del saneamiento.

\section{Ubicación de los colonos}

Como ya se ha detallado anteriormente: que para efectos de levantamiento de información de campo se dividió la zona de estudio en cuatro sectores, los referimos aquí para evidenciar la ubicación de los colonos y los límites fronterizos en el TMSA por donde ingresan.

El total de la zona cubierta incluye principalmente zona de amortiguamiento $\mathrm{y}$, en menor grado, zona núcleo de la reserva de BOSAWAS, ya que la migración de colonos es mayor en esta área. Cabe hacer mención que no se logró cubrir un área en el sector 3 debido a la falta de acompañamiento interinstitucional para terminar el levantamiento de información en este sector. Sin embargo, dada la ubicación de esta pequeña área (un $20 \%$ aproximadamente) del sector 3, en la zona conocida como El Tesoro, se considera que la información levantada hasta ahora es suficiente para hacer un diagnóstico claro y conclusivo de la situación de MSA en relación a los colonos que ocupan ilegalmente tierras de este territorio. 


\section{Grafico No.9. Mapa de ubicación de los colonos}

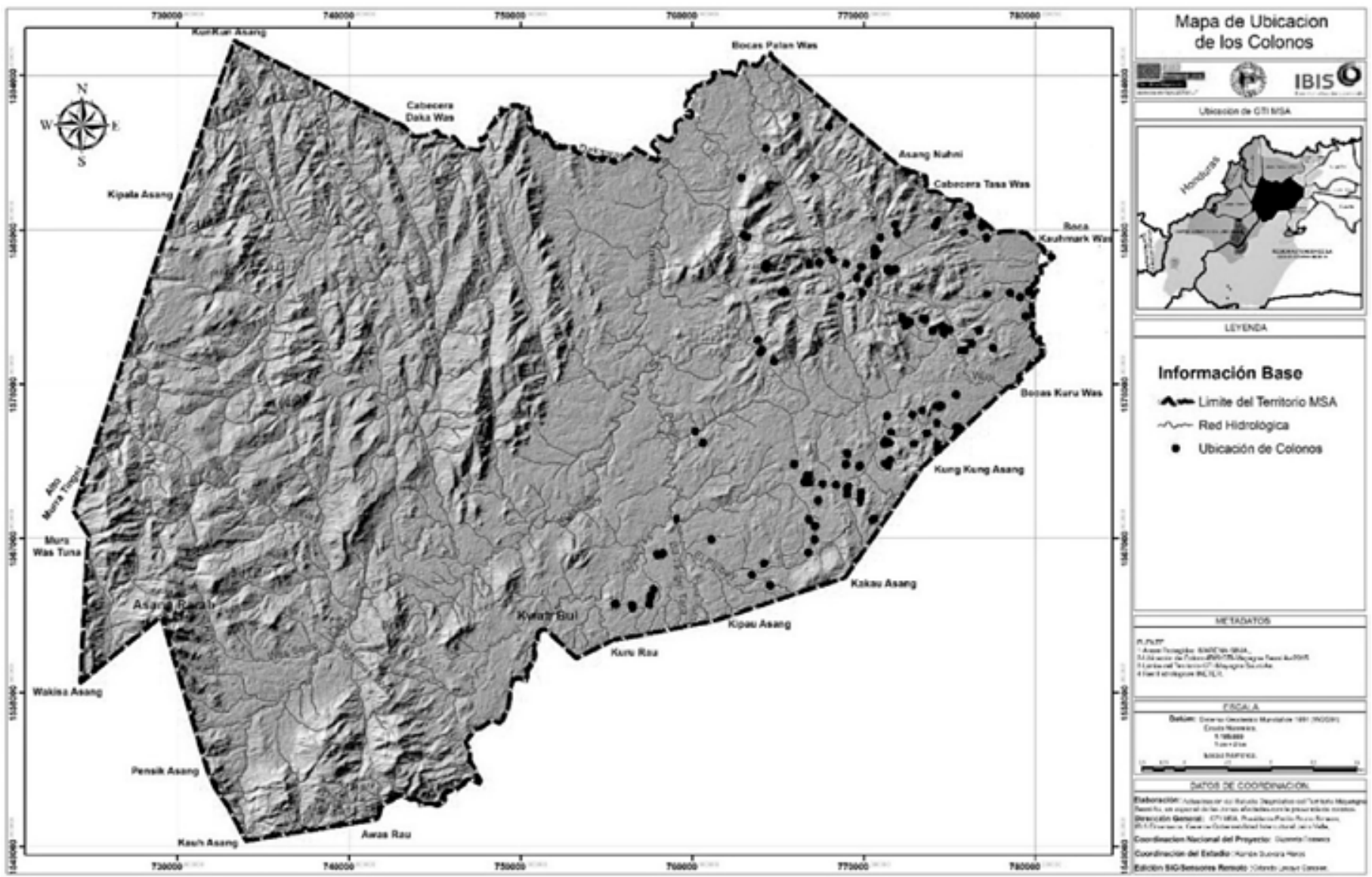

Fuente: Elaboración propia / Equipo consultor junio 2015.

El mapa de ubicación de colonos arriba mostrado señala el lugar de ocupación de 197 familias distribuidas a lo largo de los cuatro sectores de estudio; destaca el acercamiento a la zona núcleo que está únicamente detenido por la frontera natural determinada por los ríos Pispis y Waspuk, que es donde tradicionalmente se ubican las comunidades mayangnas a lo largo de los ríos. Los sectores 2 y 3 son los más afectados con la migración de colonos. Del total de encuestados, 168 colonos se ubican en estos dos sectores. Si estimamos en $20 \%$ el área que no se cubrió en el sector 3 , y partimos de que la densidad de población aquí tiene un promedio similar al del sector 2, podríamos decir con bastante seguridad que hay aproximadamente 33 familias que no fueron encuestadas y que viven en el sector El Tesoro.

La densidad de la población de colonos tiene particularidades de ocupación distintas a la de los comunitarios mayangnas. Los colonos se ubican en zonas boscosas que son convertidas en pastizales, independiente de los niveles de elevación de los suelos; así, las fincas o parcelas se encuentran en las faldas de los cerros, éste es el caso del sector 1. No es común encontrar a los colonos y sus fincas ubicadas a menos de tres kilómetros de las riberas de los ríos, lo cual sí que es una característica propia de la forma de vida mayangna. Esto se debe a que las vías de penetración de los colonos son los senderos, caminos, trochas y los mismos carriles que delimitan el territorio, es el caso de penetración en los sectores 2 y 3 y aquí hay cuatro zonas rojas, a las cuales hay que prestar especial atención en la estrategia de saneamiento, que son:

- Senderos y carriles límites con el territorio Wangki Li Aubra.

- Camino de penetración del poblado Biltingni Central, ubicado en los límites del territorio MSA con el municipio de Bonanza.

- Cabecera del río Wawa, a través de las trochas construidas para la extracción de madera por la empresa MAPINICSA, territorio AMASAU.

- Senderos y carriles del territorio MSA límite con el territorio MATUMBAK. 
Debido a que los colonos poseen entre sus bienes materiales, herramientas, ganado, mulas de carga, animales de patio, semillas, víveres para abastecer pulperías, etc.; es fácilmente deducible que las vías de acceso deben tener un mínimo de condiciones para transportar estos bienes, por lo cual no se puede afirmar que sean propiamente los ríos una vía de acceso, pero sí lo son los caminos poco estructurados que hacen límites con el territorio MSA y los municipios o territorio vecinos de Bonanza y Waspam.

\section{Formas de tenencia de la tierra}

Empecemos este acápite por rescatar la máxima del derecho Prior in tempore, potior in iure que puede traducirse del latín: "primero en tiempo es primero en derecho", lo cual en el caso de Mayangna Sauni As remite necesariamente a la inscripción No. 1455, Tomo 009, Asiento Primero, Libro de Propiedades, Sección de Derechos Reales Columna de "Anotaciones Preventivas" del Registro Público de la Propiedad de Puerto Cabezas, donde se crea el primer asiento registral de la propiedad del territorio MSA.

Debido a la característica del título otorgado bajo la calidad de propiedad comunal, las tierras del TMSA son imprescriptibles, por cuanto el derecho no se pierde con el paso del tiempo, inalienables, por cuanto las tierras no se pueden vender ni son objeto de sesión, y son tierras inembargables, en cuanto las tierras no se pueden utilizar para cubrir una deuda. Por consiguiente, podemos afirmar para efectos de nuestro análisis los siguientes dos criterios que fundamentaran nuestras exposiciones:

1. El pueblo indígena del TMSA ostenta el mejor título sobre la propiedad comunal titulada bajo No. 004-05005. Sustentado en el artículo 35 de la Ley 445, que establece que prevalecen los derechos de propiedad de las comunidades indígenas sobre título emitidos a favor de colonos que pretendan ocupar tierras comunales a partir del año 1987.

2. Por cuanto la propiedad comunal es imprescriptible, inalienable e inembargable no existe ocupación posterior a la emisión del título del TMSA que ostente mejor derecho legalmente.

Para identificar las formas de tenencia encontradas en el TMSA con este estudio, será necesario dirimir a qué tipo de ocupantes nos referimos. En ese sentido, utilizaremos para análisis los artículos 35, 36, 37 y 38 de la Ley No. 445, que se refieren a terceros - colonos en tierras comunales. Según la Ley 445, los "terceros" son todas aquellas "personas naturales o jurídicas, distintas de las comunidades, que aleguen derechos de propiedad dentro de una tierra comunal o un territorio indígena". En ese sentido, las familias que ocupan tierras en el TMSA afirmaron, en un $86.80 \%$, que no tienen ningún derecho sobre las tierras comunales que ocupan, y el $10.2 \%$ no respondió a esta pregunta pero tampoco alegó algún derecho de tenencia o propiedad, por lo cual, basándonos en el literal de la Ley 445, estas personas no deberían ser consideradas terceros, en tanto no alegan derechos de propiedad o de tenencia en estas tierras comunales, su ocupación es reciente y posterior a la titulación de MSA.

Surge entonces la pregunta de cómo pueden ser catalogados estos ocupantes y, debido a que jurídicamente solo la Ley 445 se refiere a terceros, cómo se debe aplicar legalmente esta norma según el artículo 38 que establece la existencia de terceros sin títulos en tierras comunales. Para efectos del presente estudio, el GTI TMSA ha solicitado la inclusión del concepto colonos que se cita a continuación:

Colono o colonos: "Personas naturales o jurídicas, distintas de las comunidades, que invaden un territorio indígena o afrodescendiente, titulado, y que no tienen derecho de propiedad dentro de la tierra comunal o el territorio indígena o afrodescendiente que ocupan”.

El concepto tiene la finalidad de llenar el vacío existente en la legislación nacional, para referirse a la ocupación reciente, y posterior a la titulación de los territorios indígenas y los afrodescendientes, de personas naturales o jurídicas que pretendan establecerse en tierras comunales sin poseer título alguno. En este tipo de ocupación se identifican los siguientes elementos que hacen la diferencia entre los colonos y los terceros:

- Los colonos reconocen que recién han entrado al territorio y por lo tanto no tienen posesión en el tiempo que sea anterior a la emisión del título de propiedad comunal.

- No poseen títulos válidos de mejor calidad que el debidamente inscrito por el territorio indígena $\mathrm{y}$ afrodescendiente.

- Su ocupación y uso de las tierras comunales difiere del uso tradicionalmente aprobado mediante normas de uso de suelo de los territorios indígenas y afrodescendientes, por lo tanto se ocasiona un daño medio ambiental que modifica las formas de vida de los pueblos indígenas y afrodescendientes.

- Se trata de una ocupación oportunista de personas naturales o jurídicas que buscan nuevas tierras para desarrollar sus propias actividades económicas. 
Cabe reiterar que pese a que las autoridades territoriales y comunales de MSA han insistido en hacer la diferenciación entre terceros y colonos, no existe propiamente una norma que sustente la denominación "colonos", por lo cual la conceptualización hecha aquí es una propuesta del territorio MSA y se utiliza de referencia para determinar el tipo de ocupación de estas personas.

Ahora bien, existe un 3\% de familias encuestada que afirman tener un documento legal que les da derecho sobre las tierras comunales que ocupan en el TMSA, en el inciso siguiente analizaremos el derecho de estas personas, que pasa por la definición de colonos y los derechos de éstos según la Ley 445.

La Ley 445 establece las formas de tenencias de terceros en tierras comunales que son legítimas. En el esquema anterior podemos observar que la tenencia legal de terceros, en tierras comunales, que se acepta está determinada por la existencia de un título de reforma agraria sin vicios de forma y fondo. Aunque también se reconoce el derecho de indemnización para aquellos terceros que tienen un título de reforma agraria en tierras comunales con vicios de forma o fondo, con el propósito que devuelva las tierras a la comunidad.
Finalmente todos aquellos terceros que no poseen títulos deben abandonar las tierras sin indemnización, no obstante, la Ley 445 establece una salvedad para aquellos terceros sin títulos que pretendan permanecer en tierras comunales, posterior a la titulación del territorio indígena, los cuales deberán pagar un canon de arrendamiento a la comunidad. Aquí hay que hacer un alto para decir que la permanencia de terceros sin títulos en tierras comunales pasa por el acuerdo entre las partes, lo cual involucra directamente a los dueños legítimos de las tierras comunales que son los pueblos indígenas y los afrodescendientes.

Según los resultados del presente estudio, hay seis personas naturales que ocupan tierras comunales en el TMSA y que alegan tener un documento que les otorga derechos de propiedad sobre las tierras comunales que ocupan. Los documentos alegados son: carta extendida por la alcaldía, aval (DECARAAN), documento de escritura pública otorgado por un abogado del municipio de Rosita, manuscrito de venta de tierra, aval para sacar títulos, carta simple manuscrita por venta de terreno.

De los seis documentos mencionados o presentados por los colonos, cinco son documentos que carecen de toda formalidad jurídica, por lo cual no se pueden utilizar para referir a estas personas como terceros con títulos según lo

Gráfico No.10. Derechos de colonos en tierras comunales

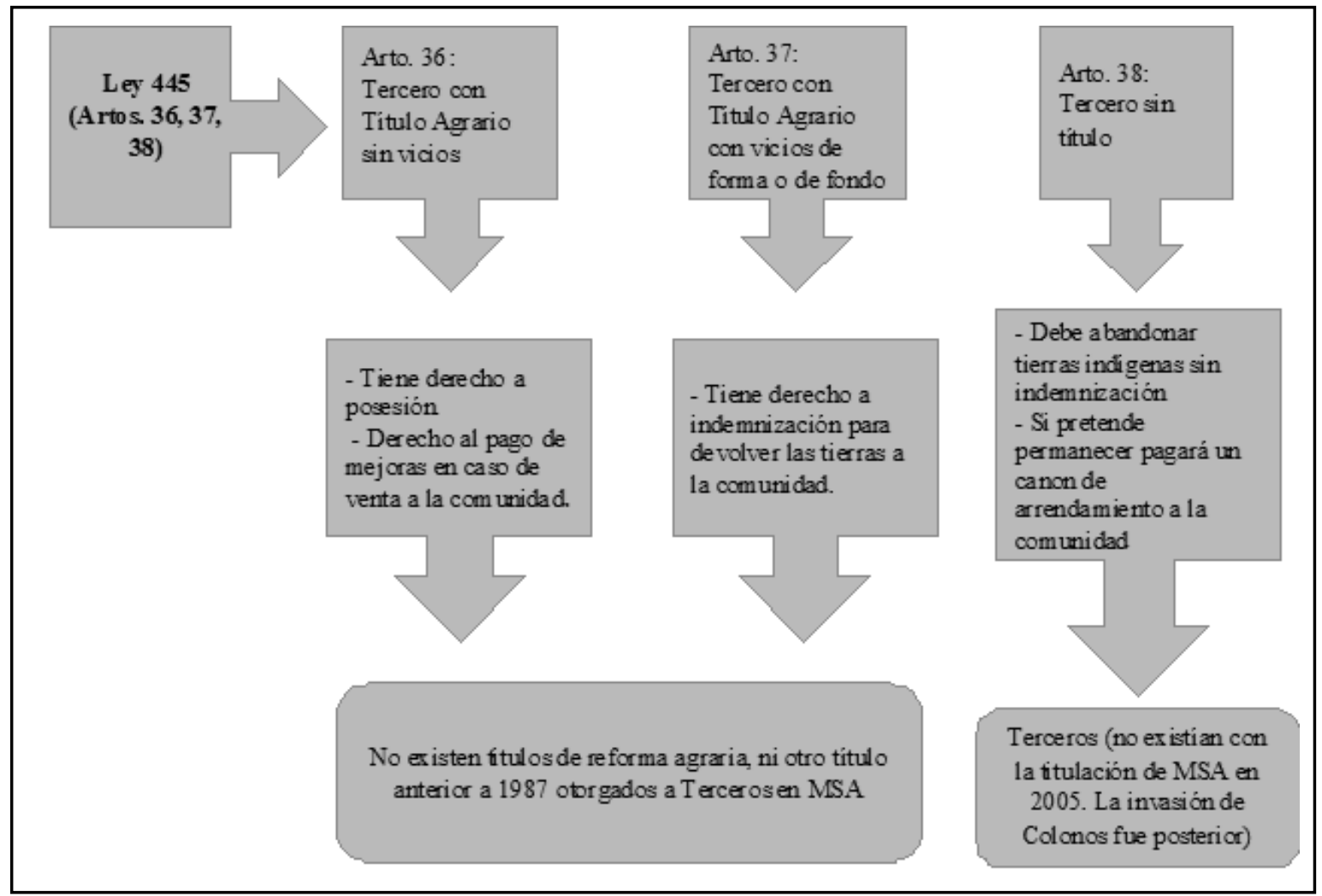

Fuente: Elaboración propia con base en la Ley No. 445. 
que determina la Ley 445; se trata simplemente de colonos invasores posterior a la titulación de TMSA. Por otro lado, existe un sólo colono que presentó una escritura pública de sesión de derechos, emitida en el año 2015 por el notario público Reynaldo Javier Blandón Aguilar con sede en el municipio de Rosita, la cual por sus características de sesión de derechos de tierras en territorio comunal indígena es ilegal y debe ser investigada para luego interponer la debida acción legal.

Recordemos que no se puede calificar de ninguna manera este tipo de escritura pública como un documento que confiere derechos de propiedad a colonos, en tanto que se otorga sobre una propiedad comunal previamente titulada que no puede ser vendida ni es objeto de sesión de derechos debido a que es inalienable.

Se debe concluir este apartado estableciendo que todas las formas de ocupación de estas 197 familias identificadas con el estudio se catalogan, según la Ley 445, como familias de colonos sin títulos, por lo cual deben abandonar las tierras de MSA sin indemnización, en razón de la falta de interés del territorio para negociar una ocupación de colonos en sus tierras comunales.

\section{Formas de acceso a la tierra}

Los medios utilizados para acceder a tierras comunales por parte de los colonos, todos se llevan a cabo al margen de la ley, es decir, de manera ilegal: el colono llega a un lugar y se posesiona de un área medida a su consideración en manzanas, despala y luego aprovecha la madera o no. Estos colonos tomas tierras que ya han establecido lotes, luego los venden por cincuenta o cien manzanas a nuevos colonos. Todo este procedimiento se realiza sin que existan documentos formales de por medio, a veces el segundo en ocupación recibe una carta manuscrita donde se hace constar la transacción. Finalmente, las áreas o lotes vendidos se convierten tarde o temprano en potreros con mejoras de interés para nuevos colonos. A continuación se presenta el detalle de los procedimientos utilizados por colonos para acceder a tierras comunales en MSA:

Tomas tierras ilegales: Están organizadas por grupos de traficantes de tierras. Generalmente forman colectivos o cooperativas informales (DECARAAN), sin ningún asidero legal se auto asignan la tenencia de la tierra y solicitan a las alcaldías municipales avales para validar su tenencia políticamente. Muchos de los colonos de El Tesoro participaron en un tranque en el año 2013 con el propósito de demandar que se les legalizaran las tierras que ocupan en el TMSA. El tranque fue levantado debido a que los colonos firmaron un acuerdo con distintas instituciones públicas del municipio de Siuna, en el cual se establece que se creará una comisión de mestizos para seguir los acuerdos sostenidos en el año 2010; se establecen reuniones con las autoridades municipales de Bonanza y se orienta a las familias volver a sus hogares y no permitir nuevas entradas de colonos.

La firma de este documento carece de la presencia del GTI TMSA, siendo la autoridad de este territorio y principal afectado con la ocupación de los colonos, de igual forma el documento por sí mismo no es suficiente para validar la tenencia de la tierra ocupada por los colonos, pero sí les da la seguridad a éstos de que las instituciones públicas conocen de su solicitud y no realizaron acciones para sacarlos. El delito de usurpación está tipificado en el Código Penal, por lo cual en este caso puede ser argumentado por el TMSA a partir de los artículos 241 del CP, Capítulo VII, de la Usurpación, y 244 Capítulo VIII de los Daños.

Cuidadores o mozos: Aunque no se encontraron muchos casos, los mozos alegan cuidar las tierras de dueños que están en El Tesoro, en La Cruz de Río Grande o en Rosita. Habitualmente cuidan fincas despaladas y viven en chozas que no tienen condiciones para habitarse. Se trata de personas que reciben un salario por el cuido de estas fincas de otros colonos en tierras comunales.

Sesión de derechos o compra y venta fraudulenta de tierras comunales: Generalmente, los toma tierras ya establecidos desarrollan los procesos de sesión de derechos de tierras o compra venta al margen de todo el ordenamiento jurídico nacional, utilizando la medida establecida por la reforma agraria, por lo cual realizan transacciones con los nuevos colonos, tomas tierras por 50 manzanas, que son vendidas entre 1,000 y 2,000 córdobas por manzana. Los colonos organizados, una vez que venden las tierras vuelven a realizar todo el proceso en nuevas tierras del TMSA. Por ello es común encontrar toma tierras que ingresaron recientemente en el sector 1 del TMSA y que le compraron las tierras comunales a los tomas tierras que viven en El Tesoro, Rosita, Bonanza, La Cruz de Río Grande, etc. El delito de estafa está tipificado en el Código Penal, por lo cual en este caso puede ser argumentado por MSA, artículos 284 y 289 del CP, Capítulo I, de la Falsificación de Documentos.

Usurpación de bienes colectivos de los pueblos indígenas: Representa el procedimiento más común utilizado por los colonos para adueñarse de las tierras comunales en el TMSA. Este procedimiento trae consigo bastante daño a la propiedad comunal, siendo que se destruyen e invisibilizan los límites del territorio, se daña y modifica la flora y fauna con el despale que obliga a las especies animales a migrar a 
otras zonas del territorio, y se despoja a los mayangnas de su pleno dominio sobre las áreas que ocupan los colonos en tanto no pueden usar, gozar y disfrutar plenamente de esta área del territorio debido a la ocupación de los colonos. El delito de usurpación está tipificado en el Código Penal, por lo cual en este caso puede ser argumentado por MSA en virtud de los artículos 241 del CP, Capítulo VII, de la Usurpación, y 244 Capítulo VIII de los Daños.

\section{Análisis de la situación jurídico legal de los colonos}

Se ha dividido esta sección en dos aspectos sobre la conflictividad que plantea el saneamiento territorial determinado por la Ley No. 445, como la V etapa del proceso de titulación de territorios indígenas y afrodescendientes, los cuales son el conflicto legal que implica el saneamiento para los colonos y el conflicto social que implica el saneamiento para hombres, mujeres, jóvenes y niños.

\section{Conflictividad legal del saneamiento para los colonos}

Nos hemos referido anteriormente a las rutas de acceso y las formas de ocupación de los colonos en MSA, también hemos analizado su situación legal y sus respectivas formas de tenencia. En este apartado vamos a analizar cómo estos aspectos incidirán y determinarán el proceso de saneamiento en el TMSA y esbozaremos algunos conflictos socio-políticos que se identifican rápidamente y que deben ser atendidos por el territorio para avanzar en la $\mathrm{V}$ etapa del proceso de titulación, que es el saneamiento territorial.

Primero hay que partir por decir que los colonos identificados son bastante distintos en cuanto a formas de ocupación y en relación a las vías de acceso que utilizan para entrar al territorio. La sectorización del territorio, según las áreas afectadas, es bastante acertada en tanto permite establecer las siguientes diferencias entre grupos:

Colonos sector 1: Se trata de colonos muy recientes, con un máximo de dos años de ocupación de tierras comunales, que entraron en el territorio atraídos por las promesas de compra venta o sesión de derechos que les ofrecen los colonos traficantes de tierras que ocupan los sectores 2 y 3 , o que viven fuera del territorio. Ninguno de estos ocupantes colonos presenta un título de propiedad válido según lo que determina la Ley 445 y algunos de ellos se encuentran organizados en DECARAAN que es la organización a través de la cual deciden la cantidad de tierra que se auto asignan. Ingresan al territorio desde Wangki Li Aubra y el sector 3 del TMSA.

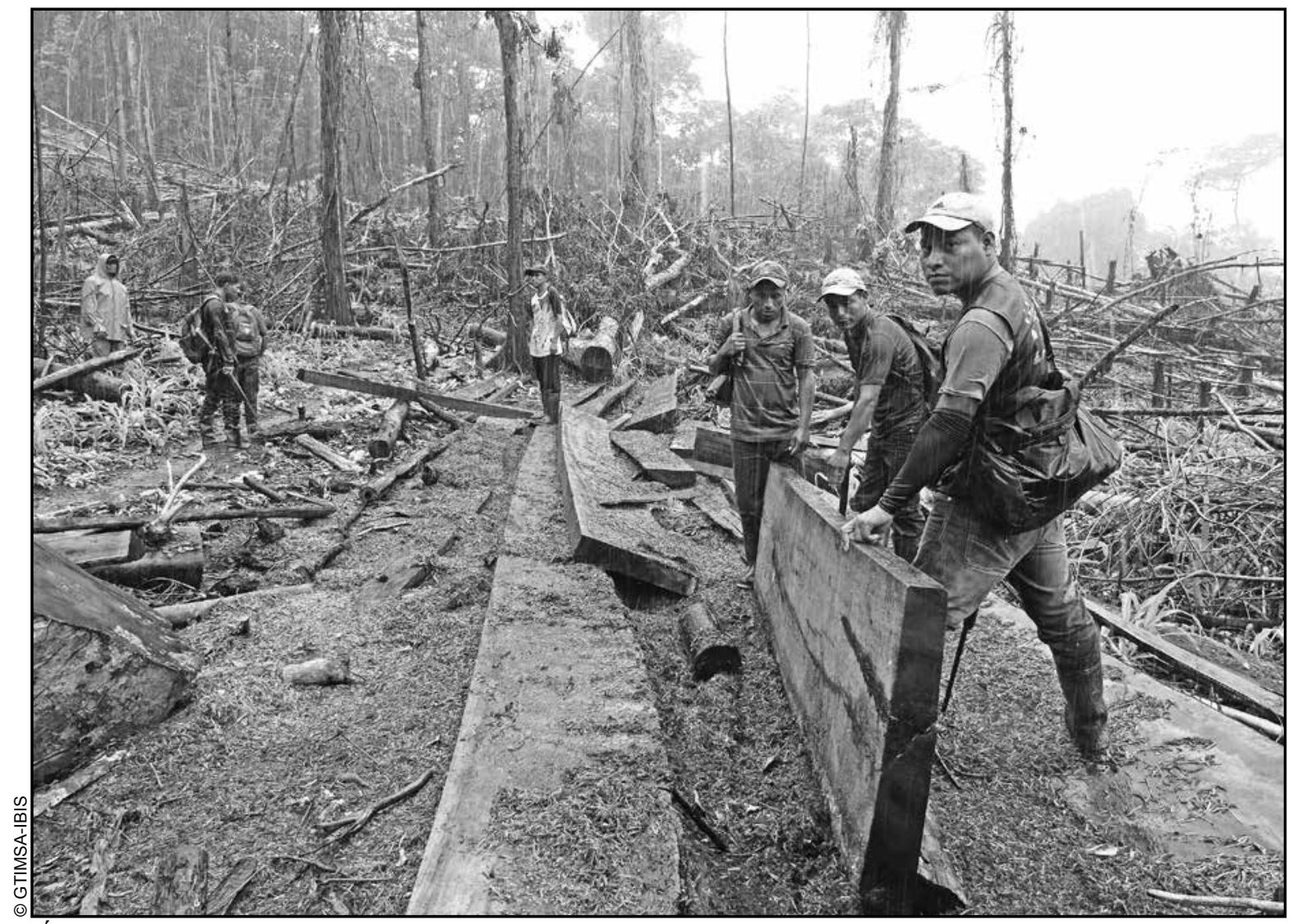

Área despalada por los colonos. Se aprecian indicios de uso de sierra para tal fin 
Conflictividad: En su mayoría reconocen que no tienen título de propiedad que respalde su tenencia, algunos son cuidadores o mozos y no están conscientes del daño que causan al medio ambiente: han interrumpido las formas de vidas de la fauna en tierras muy altas al motivar una migración interna de aves, animales salvajes y los mamíferos que viven en las ramas de los árboles; sus fincas se asientan en medio de cerros boscosos a escasos metros de caños; los troncos de árboles evidencian en la totalidad de los casos que fueron cortados con motosierra; no existe evidencia visual del aprovechamiento de la cantidad de madera cortada. Su permanencia en el territorio está motivada por la búsqueda de nuevas tierras que se cotizan baratas, en algunos casos manifestaron su disponibilidad para salir del territorio si el gobierno central los reubica. Políticamente no expresan respaldo de autoridades municipales, regionales o del gobierno central.

Colonos sector 2 y 3: Analizaremos en conjunto a estos dos grupos de colonos pues son muy similares entre ellos en el tema que nos ocupa: tienen en promedio cinco años de ocupación de tierras comunales en estos dos sectores; entraron en el territorio motivados por el tráfico de tierra y en la búsqueda de tierras "libres"; constantemente se encuentran inmersos en la comercialización de tierras, lo cual demuestran mediante el hospedaje de nuevas familias que esperan ser reubicadas; sus viviendas están bien estructuradas y cuentan con capillas o iglesias de oración y solicitan al gobierno municipal la construcción de escuelas y centros de salud; poseen bienes de alto costo (paneles solares, motosierras, rifles, armas de fuego, etcétera).

Conflictividad: Ninguna de las personas encuestadas presentó un documento legal que respalde su tenencia según lo que determina la Ley 445 (ya se analizó el caso de la única escritura pública encontrada, véase punto 5.2). Debido a que su ocupación tiene ya varios años es bastante difícil especificar el grado del daño causado al medio ambiente ya que, principalmente, en el sector 3 se aprecian grandes fincas con pastizales. En validación de información, los líderes mayangnas especificaron que en este sector había una zona de desarrollo, que era aprovechada por las comunidades cercanas. Los colonos que ocupan estos sectores expresan estar respaldados por las autoridades municipales y presentan un acuerdo firmado con autoridades de distintas instituciones del triángulo minero en el año 2013 (Véase el punto 5.3 de formas de acceso a las tierras comunales). Tienen intención de asentarse en las tierras comunales que ocupan.

Colonos sector 4: Se identifican como colonos con más de diez años de ocupación, son constantemente visitados por el GTI TMSA. Afirman que llegaron al territorio motivados por la autorización de líderes de Sikilta. Uno de ellos se encuentra en el límite del territorio; otro, al interno del territorio. Están anuentes a informar constantemente al GTI sobre la entrada de nuevos colonos y mencionan sobre su apoyo para la identificación de nuevas familias que ingresaron al territorio en meses pasados y fueron desalojados por el BECO.

Conflictividad: Ninguna de las personas encuestadas presentó un documento legal que respalde su tenencia según lo que determina la Ley 445. Debido a que su ocupación se realiza en pequeñas porciones de tierras no se puede señalar el daño que ocasionan al bosque de esta zona. Reconocen que ocupan tierras comunales indígenas y que su tenencia es ilegal.

\section{Conflicto social que implica el saneamiento para hombres, mujeres, jóvenes y niños}

Las mujeres y niños son los integrantes de estas familias que están más expuestos, ya que su ocupación les obliga a vivir con las mínimas condiciones de sanidad y sin acceso a educación y servicios de salud. Las mujeres están confinadas a las labores domésticas por cuanto las actividades económicas que se desarrollan en estos sectores implican un trabajo físicamente exigente en las montañas o el campo. Los niños muchas veces son muy pequeños, andan desnudos en sus hogares sobre pisos de tierra, expuestos a las picaduras de insectos y otros animales rastreros.

Por otro lado, la situación legal de niños y mujeres se ve comprometida casi siempre por la forma de tenencia del hombre cabeza de familia, de manera que también se encuentran en situación de tenencia ilegal. Es muy extraño que las mujeres expresen su opinión sobre su ocupación en tierras comunales, pero cuando lo hicieron en el sector 1 se mostraron anuentes para salir del territorio si eran reubicadas.

En el caso de las mujeres que ocupan los sectores 2 y 3 solicitan la construcción de escuelas para que sus hijos no queden fuera del sistema escolar y su intención es organizarse para defender sus intereses en relación a las tierras comunales que ocupan. Una estrategia de saneamiento deberá considerar a estos miembros de las familias de colonos, principalmente en el caso de familias con niños muy pequeños y vulnerables. El saneamiento que implique desalojo deberá evitar casos de violencia cuando hay menores de edad en las familias de colonos. No obstante, es necesario mencionar que no se trata de la mayor parte de las familias de colonos.

Habría que dirimir claramente que las familias de colonos con integrantes menores de edad representan una doble 
problemática para el saneamiento, ya que obligarán al territorio MSA a implementar una estrategia que los considere y el saneamiento que implique desalojo en este caso podría llevar más tiempo si no es voluntario, por otro lado la falta de acciones de MSA alrededor de estas familias ha sido la oportunidad para que estos colonos soliciten mayor atención y presencia institucional lo que de realizarse deviene a largo plazo en una ocupación indefinida en el tiempo.

\section{Mecanismos de resolución de conflictos y acciones legales propuestas}

Existen distintas posibilidades para que los territorios indígenas y afrodescendientes impulsen su proceso de autosaneamiento. En función de ello se ha creado la Comisión interinstitucional para la defensa de la Madre Tierra en territorios indígenas y afrodescendientes del Caribe y Alto Wangki Bocay, mediante el Decreto 15-2013. Esta comisión actúa como apoyo interinstitucional para impulsar el proceso de saneamiento territorial. Especial atención merecen aquellos territorios que poseen áreas protegidas, tal es el caso de Mayangna Sauni As con más del $40 \%$ de su territorio como parte integrante de la zona núcleo de BOSAWAS y un $56 \%$ como zona de amortiguamiento.

Todo conflicto entre dos partes requiere de la construcción de un diálogo en la búsqueda de un acuerdo para considerarse exitoso, o bien, agotado el diálogo ofrece la pauta para avanzar al uso de otras acciones posibles en respuesta al conflicto. Es así como la resolución alterna de conflictos se convierte en una estrategia viable para agotar el diálogo en la búsqueda de un acuerdo para el saneamiento territorial, que en Mayangna Sauni As pasa por el desalojo según la intención de sus autoridades territoriales.

La Ley 445 abre las puertas a la voluntad de cada territorio indígena $\mathrm{o}$ afrodescendiente para iniciar el saneamiento o bien el autosaneamiento con el apoyo de la OTR, que funciona como parte de la PGR (Procuraduría General de la República). En congruencia con el Decreto 15-2013 se establece en el artículo 4 inciso d), que como parte de las funciones de la Comisión Interinstitucional para la Defensa de la Madre Tierra se debe ejercer en lo posible la mediación y la solución alternativa en los casos de conflictos que involucren a colonos, y para ello ya el artículo 2 del mismo Decreto establece la salvedad que se debe priorizar la defensa de la madre tierra de aquellos territorios donde existan áreas protegidas.

Este escenario jurídico obliga a pensar en el contexto actual del TMSA, siendo parte integrante del área protegida más importante de Nicaragua, teniendo como principal objetivo proceder al desalojo para restaurar sus bosques y viéndose inmersa en el área geográfica con la mayor presión a nivel nacional para el avance de la frontera agrícola. El escenario se complejiza si tomamos en cuenta que existe una congruencia interinstitucional, en torno al territorio, con obligaciones y responsabilidades distintas y que en mayor o menor medida muestran un nivel de compromiso con la conservación de los recursos naturales. Antes de proponer un mecanismo de resolución de conflictos y acciones legales pertinentes necesitamos conocer el mapa de actores según los ejes de acción, de tal forma que dejemos establecidas las responsabilidades interinstitucionales de cara al territorio.

\section{Trámites de mediación que conlleven al desalojo}

Se propone la realización de un proceso de incidencia sostenido y consistente en el tiempo para lograr el desalojo inmediato de los colonos que ocupan tierras comunales en el sector 1, debido a que ésta es un área de conservación del TMSA y se encuentra a escasos kilómetros de la zona núcleo de la Reserva de BOSAWAS. Los colonos no demostraron ni evidenciaron ninguna forma de respeto por los recursos naturales de esta zona y su permanencia en la misma significa por si sola una amenaza constante para la reserva. El GTI del TMSA debe desarrollar una estrategia de saneamiento que contemple la realización de una incidencia interinstitucional a nivel nacional, ya que el resguardo de esta zona requiere una respuesta institucional inmediata.

Con la mediación o resolución alterna de conflictos con los colonos que ocupan tierras comunales en los sectores 2, 3 y 4 se podría alcanzar el desalojo en un plazo medio (un año) o a largo plazo (dos o más años). Debido a que existe bastante resistencia de este grupo de colonos para mediar con los comunitarios de MSA, se requerirá iniciar un proceso de comunicación con los colonos e incidencia institucional sobre los derechos territoriales de MSA, para proceder posteriormente a la mediación y alcanzar un acuerdo para el abandono voluntario de las tierras.

La realización de estos procedimientos debe ser notificada a la Comisión de Defensa de la Madre Tierra y en la medida de lo posible debe contar con el apoyo de esta Comisión para su realización. No obstante, el TMSA no está obligado a aceptar la permanencia de los colonos más allá de los plazos que considere razonables y que lo sean dentro de la consideración del bienestar humano.

\section{Trámites legales que conlleven al desalojo}

Será necesario que el territorio MSA incluya dentro de su estrategia de saneamiento un perfil completo de los traficantes de tierras, utilizando de base la información recopilada con el autodiagnóstico. Adicionalmente, llevar a cabo la estrategia de saneamiento obliga al GTI TMSA a completar el levantamiento de información pendiente en el sector 3 del territorio, que es donde viven, transitan o se ocultan los traficantes de tierra. La dinámica de 
Gráfico No. z11 Actores y vinculación jurídica en el Proceso de Saneamiento Territorial

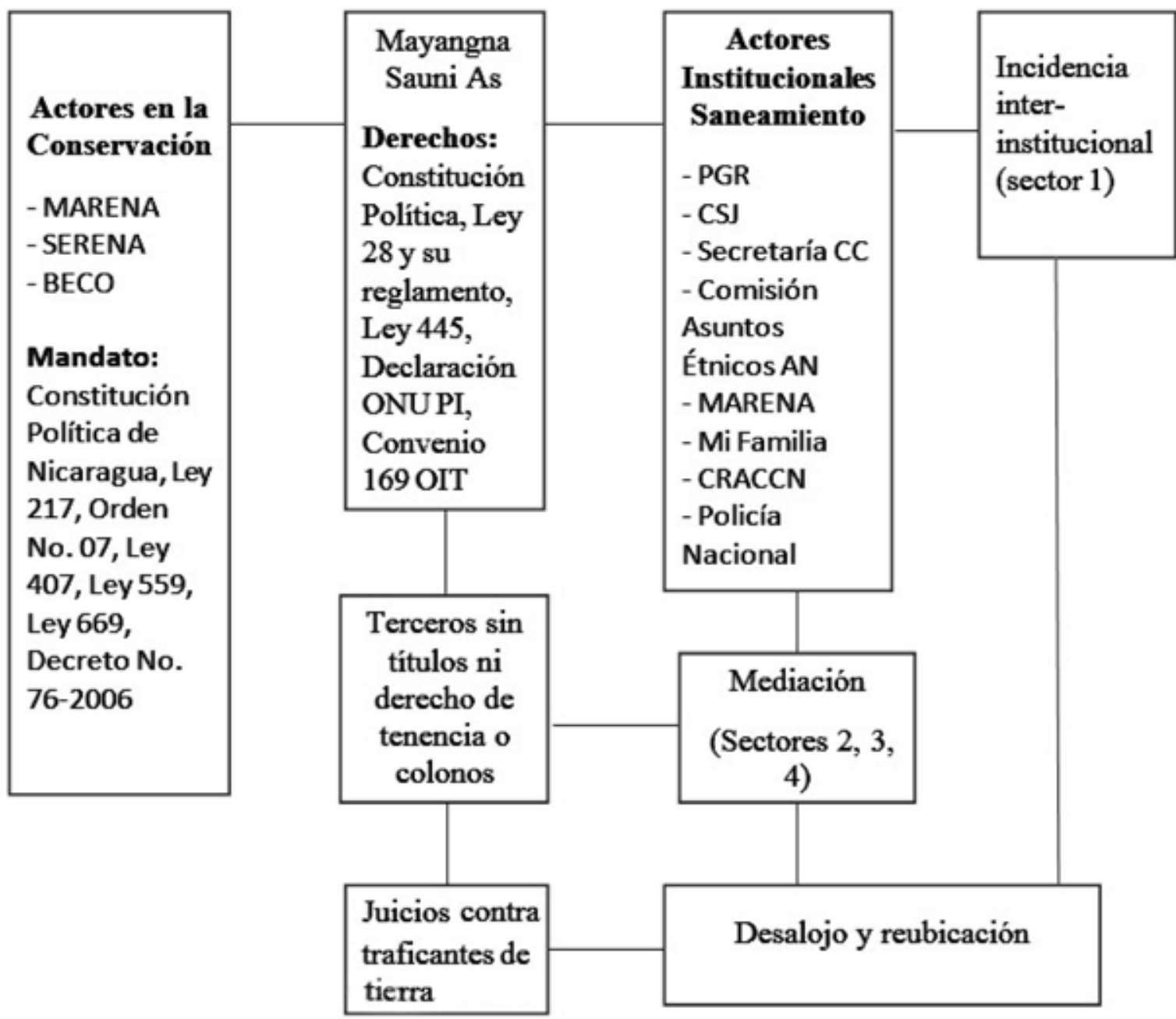

Nota: Normas jurídicas Relacionadas en el esquema

Constitución Política de Nicaragua

Ley No. 28 Estatutos de Autonomía de las Regiones Autónomas de la Costa Atlántica

Ley No. 445. Ley del Régimen de la Propiedad Comunal de las Comunidades Indígenas y Étnicas de la Costa Atlántica de Nicaragua de los ríos Coco, Bocay, Indio y Maíz en 2003.

Declaración de las Naciones Unidas sobre los derechos de los pueblos indígenas

Convenio 169 de la OIT sobre pueblos indígenas y tribales en países independientes

La Ley 217, Ley general del medio ambiente de 27 de marzo de 1996.

Decreto 44-91, Reserva Nacional de los Recursos Naturales de Bosawas el 31 de octubre de 1991.

Reforma al Decreto NO. 44-91 Que declara la reserva nacional de recursos naturales BOSAWAS, Decreto No. 32-96, Aprobada el 05 de diciembre de 1996.

Ley 407, Ley de Biosfera de Bosawas el 18 de diciembre del 2001.

La Ley 559, Ley de Delito Ambiental el 18 de noviembre del 2005.

Ley No. 669, Ley de Conservaciones del uso de los suelos en la Reserva de la Biosfera de Bosawas. Aprobada el 9 de Septiembre de 2008.

Decreto No. 76-2006, Sistema de Evaluación Ambiental en Nicaragua el 19 de noviembre del 2006.

Código Penal de Nicaragua.

Orden No. 07 del 28 de enero del año 2011 "Creación del Batallón Ecológico del Ejército de Nicaragua”. 
acciones legales responde a los procedimientos judiciales emprendidos desde el GTI TMSA con su asesor legal, siendo la naturaleza de los principales delitos: ambientales y de usurpación de la propiedad comunal.

Por lo tanto es necesario identificar la cadena seguida por los traficantes de tierras, para vender y traer a nuevos colonos, y desarticularla mediante el enjuiciamiento de los líderes de estas organizaciones y la vigilancia constante de las rutas utilizados por éstos para ingresar al territorio. De igual forma debe iniciarse a lo inmediato las investigaciones policiales para determinar el grado de culpabilidad por falsificación de documento público en el caso de los abogados que extienden escrituras públicas a petición de los traficantes de tierras.

\section{RECOMENDACIONES GENERALES}

A continuación se presentan las propuestas para una estrategia para el saneamiento a partir de la validación de información del estudio diagnóstico con la asamblea territorial, técnicos consultores y GTI TMSA:

\section{Acciones a corto plazo $(<1$ año)}

Realizar patrullajes constantes en los sectores ocupados por los colonos: Requerirá del acompañamiento interinstitucional, recursos financieros y una estrategia de delimitación del territorio estrechamente vinculada con los vecinos oficiales de los límites fronterizos (Wangki Li Aubra, AMASAU, MATUMBAK, Sikilta; Biltingni Central). Aunque esta actividad se debe mantener en el tiempo es necesario que en este primer año sea más intensiva.

Mantener la asesoría legal permanente de tal forma que los procedimientos judiciales contra los traficantes de tierras se puedan sostener en el tiempo. Esta otra actividad que debe permanecer en el tiempo deberá requerir de una mayor participación en el primer año.

Crear una comisión de tierra para que evalúe el daño ambiental causado por los colonos y que apoye al GTI en las negociaciones e incidencia a nivel interinstitucional.

El GTI-MSA debe dirigir cartas a las alcaldías de Rosita y Bonanza, demandando frenar las acciones vandálicas de los toma tierras, porque estos invasores tienen intención de construcción de escuela y capilla en áreas que están usurpando.

Realizar un proceso judicial contra los traficantes de tierra del territorio Mayangna sauni As que se identificaron en este estudio y renovar las órdenes de captura contra los prófugos que han vendido tierras en el territorio Sauni As.

Abrir el carril y amojonar entre los puntos Kungkung Asang y Kauhmakwas Sahni debido a que en este tramo no hay carril, por esta situación los usurpadores de tierra entran con toda libertad vía municipio de Rosita.

Como parte de la actualización del diagnóstico se propone que se revise la propuesta del mapa de zonificación que se incluye en este estudio y que tiene como base el aprobado en el 2011. Esta propuesta se basa en la necesidad de conservar áreas que están actualmente amenazadas por los invasores y que quizás requieren una categoría de uso más restringida. La importancia de ajustar las zonas de uso se da por diferentes razones (conservación de fuentes claves de recarga hídrica, hotspots de alta biodiversidad, reforestación o regeneración de cuencas importantes para evitar la continua erosión y/o restaurar el suelo afectado por las actividades de los colonos, etc.)

\section{Acciones a mediano plazo ( $>1$ año)}

- Establecer puestos de control a lo largo de la frontera del territorio, especialmente en aquellos puntos estratégicos para el ingreso a la zona núcleo de la RBB. Aunque esto implica costos muy altos, debe ser una propuesta a presentar al gobierno central, aunque también se puede valorar que el TMSA aporte con personal calificado para garantizar esta propuesta.

- Realizar un proyecto de conservación y protección de la reserva Biosfera Bosawas

- Desarrollar plan de reforestación con árboles preciosos en las áreas despaladas por los usurpadores de tierras indígenas.

- Manejo de fauna silvestre en peligro de extinción en la zona de la reserva.

- Manejo de cuencas, subcuencas y micro cuencas, afectadas por los invasores

- Establecer, en los puntos de entrada de los colonos al TMSA, asentamientos de familias jóvenes indígenas con el apoyo decidido de todas las organizaciones a nivel municipal. Cabe señalar que existen experiencias exitosas, como la que se está proponiendo en Sudamérica, que sería bueno que el GTI tuviera acceso a documentación al respecto.

- A partir del analisis legal se identificó que la Ley 445 no tiene alcance para tratar a los colonos o invasores que entran post-titulación en los territorios indigenas y afrodescendientes, ya que su acción llega hasta el 
momento del saneamiento territorial como parte del proceso de titulación. Por consiguiente, la seguridad jurídica del derecho de propiedad comunal indígena y afrodescendiente, legitimamente ejercido y titulado, se remite al Código Penal donde se establecen penas de prision para quien usurpe la propiedad comunal. No obstante, no existe en las leyes vigentes en el pais una accion legal que se pueda emprender para que los territorios indigenas y afrodescendientes recuperen el pleno dominio y posesion de la propiedad comunal, una vez usurpada por invasores o colonos. Se recomienda en ese sentido una reforma al Codigo Procesal Civil de Nicaragua, a manera de contemplar el desahucio o lanzamiento para aquellos colonos o invasores que usurpen la propiedad comunal de pleno dominio y posesion de los territorios indigenas y afrodescendientes.

\section{Bibliografía consultada}

Barié, Cletus Gregor. 2003. Pueblos Indígenas y Derechos Constitucionales en América Latina: un panorama, Bolivia. Internet: http://gregor.padep.org.bo/pdf.htm (5.10.2010).

Bataillon, Guilles. 2001. Cambios culturales y sociopolíticos en las comunidades Mayangnas y Miskitus del río Bocay y del alto río Coco, Nicaragua (1979-2000); en: Journal de la Socienté des Américanistes, http://jsa.revues.org/index1238.html (5.10.2010).

BID. 2003: Información sobre los Pueblos Indigenas de Nicaragua como insumo para el Proyecto Regional de Manejo Integrado de Ecosistemas por Pueblos Indígenas y Comunidades de Centroamérica.

Bonilla Toruño Alejandro. 2009. "Tráfico ilegal de tierras en la Reserva de Biósfera Bosawas, Un Estudio Jurídico Sobre el Sistema de Tenencia de la Tierra".

Canal 8. 2010. Reportaje especial: Emergencia en Bosawas en Esta Semana, enero del.

Carol R.Ember y Melvin Ember. 1997. Antropología Cultural. Prentice, Hall, Madrid,

CEDJUHCAN -CONADETI. "Manual de Saneamiento" (Versión Borrador).

Centro Humboldt. 2016. "Crisis Socioambiental de Nicaragua".

Cordón Ma. Y Toledo V. 2012. "El uso múltiple de las comunidades indígenas de BOSAWAS como germen para el desarrollo".

Gobierno Territorial Rama y Kriol. 2009. "Diagnóstico del Territorio Rama - Kriol” (Presentación en Power Point).

GIZ MARENACE PDCMIT MSA 2011.

GTZ-GFA, Alexis Sánchez. 2007: "Análisis Multitemporal de Imágenes Satelitales en RAAN y Suroeste de Nicaragua de los períodos $1987-2000$ y $2005 "$ ".

GFA Consulting tráfico Ilegal de tierras en BOSAWAS. Wolfgang A. 2009.

GTI Mayangna Sauni Arungka. Factibilidad de la etapa de saneamiento... Wolfgang A. 2010.

Guevara, Ramón, Planificación para el Desarrollo Territorial de las comunidades indígenas y mestizas del Municipio de Prinzapolka a partir del Ordenamiento de su territorio y tomando como base sus medios de vida. Agosto 2007.

Instituto Nacional de Estadísticas y Censos (INEC): VIII Censo de Población y IV de Vivienda 2005, Nicaragua, 2006.

IWGIA: Indigenous Worlds, 2009.

Ley 445 www.poderjudicial.gob.ni/pjupload/costacaribe/pdf/Ley_445.pdf

MASAGNI Diagnostico Saneamiento Wolfgang A. Abril 2013.

Programa de las Naciones Unidas para el Desarrollo, NIcaragua Informe de Desarrollo Humano,2005

PRODEP Aseguramiento de los derechos de propiedad comunal .... MAGFOR 2010.

Programa GIZ - MASRENACE / GFA Consulting Group. Sistematización de prácticas desarrolladas en el proceso de saneamiento territorial TMSA y TMSB. 2013.

Roiz, R. Caracterización de la zona prioritaria de Bosawas - Informe Técnico Proyecto Establecimiento de un Programa para la Consolidación del Corredor Biológico Mesoamericano SICA-CCAD PNUD-GEF GTZ. s/f.

Navarete C., Alfonso, 2000: Caracterización fisio-geográfica y demográfica de las regiones autónomas del Caribe deNicaragua. Fundación para la Autonomía y Desarrollo de la Costa Atlántica de Nicaragua FADCANIC.

http://wwwds.worldbank.org/external/default/WDSContentServer/WDSP/IB/2006/05/30/000160016_20060530175058/Rendered/ INDEX/IPP1720v2.txt 